\title{
Identification of prothymosin alpha (PTMA) as a biomarker for esophageal squamous cell carcinoma (ESCC) by label-free quantitative proteomics and Quantitative Dot Blot (QDB)
}

Yanping Zhu ${ }^{1 \dagger}$, Xiaoying Qi ${ }^{1 \dagger}$, Cuicui Yu ${ }^{2 \dagger}$, Shoujun Yu ${ }^{3}$, Chao Zhang ${ }^{1}$, Yuan Zhang ${ }^{1}$, Xiuxiu Liu ${ }^{1}$, Yuxue Xu', Chunhua Yang ${ }^{1}$, Wenguo Jiang ${ }^{1}$, Geng Tian ${ }^{1}$, Xuri Li ${ }^{4}$, Jonas Bergquist ${ }^{1,5}$, Jiandi Zhang ${ }^{1,6}$, Lei Wang ${ }^{7 *}$ and Jia Mi ${ }^{{ }^{*}}$

\begin{abstract}
Background: Esophageal cancer $(E C)$ is one of the malignant tumors with a poor prognosis. The early stage of $E C$ is asymptomatic, so identification of cancer biomarkers is important for early detection and clinical practice.

Methods: In this study, we compared the protein expression profiles in esophageal squamous cell carcinoma (ESCC) tissues and adjacent normal esophageal tissues from five patients through high-resolution label-free mass spectrometry. Through bioinformatics analysis, we found the differentially expressed proteins of ESCC. To perform the rapid identification of biomarkers, we adopted a high-throughput protein identification technique of Quantitative Dot Blot (QDB). Meanwhile, the QDB results were verified by classical immunohistochemistry.

Results: In total 2297 proteins were identified, out of which 308 proteins were differentially expressed between ESCC tissues and normal tissues. By bioinformatics analysis, the four up-regulated proteins (PTMA, PAK2, PPP1CA, HMGB2) and the five down-regulated proteins (Caveolin, Integrin beta-1, Collagen alpha-2(VI), Leiomodin-1 and Vinculin) were selected and validated in ESCC by Western Blot. Furthermore, we performed the QDB and IHC analysis in 64 patients and 117 patients, respectively. The PTMA expression was up-regulated gradually along the progression of ESCC, and the PTMA expression ratio between tumor and adjacent normal tissue was significantly increased along with the progression. Therefore, we suggest that PTMA might be a potential candidate biomarker for ESCC.
\end{abstract}

Conclusion: In this study, label-free quantitative proteomics combined with QDB revealed that PTMA expression was up-regulated in ESCC tissues, and PTMA might be a potential candidate for ESCC. Since Western Blot cannot achieve rapid and high-throughput screening of mass spectrometry results, the emergence of QDB meets this demand and provides an effective method for the identification of biomarkers.

Keywords: Esophageal squamous cell carcinoma (ESCC), Label-free quantitative proteomics, Prothymosin alpha (PTMA), Quantitative Dot Blot (QDB)

\footnotetext{
*Correspondence: 15045806158@163.com; jia.mi@kemi.uu.se

†Yanping Zhu, Xiaoying Qi and Cuicui Yu authors contributed equally to this study and share first authorship

1 Precision Medicine Research Center, Binzhou Medical University, No. 346 Guanhai Rd., Laishan District, Yantai 264003, Shandong Province, People's Republic of China ${ }^{7}$ Department of Thoracic Surgery, The First Affiliated Hospital of Harbin Medical University, No. 23, Youzheng Street, Nangang District, Harbin 150000, Heilongjiang Province, People's Republic of China Full list of author information is available at the end of the article
} 


\section{Introduction}

Esophageal cancer (EC) is one of the malignant tumors with a 5 -year survival incidence of $20.9 \%$ [1, 2]. EC is ranked as the eighth most common malignant tumor with the sixth highest mortality rate worldwide. There are two histological subtypes of EC: esophageal squamous cell carcinoma (ESCC) and esophageal adeno carcinoma (EAC). ESCC often occurs in the top or middle of the esophagus, and starts in the flat thin cells that make up the lining of the esophagus. Meanwhile, EAC is most common in the lower portion of the esophagus, and starts in the glandular cells that are responsible for the production of fluids such as mucus. China is a high-risk area for EC, and more than $90 \%$ of cases are esophageal squamous cell carcinoma (ESCC) [3-5]. Moreover, most of the patients exhibit locally advanced or metastatic EC at the time of being diagnosed $[6,7]$. Therefore, it is urgent to discover biomarkers for early clinical diagnosis to improve survival.

Esophageal cancer biomarkers have been found in saliva, blood, and urine. Sedighi et al. showed that the serum level of Matric metalloproteinase (MMP)13 in ESCC patients were significantly higher than in the control group, and suggested that the MMP-13 was associated with increasing ESCC invasion, lymph node involvement and decreased survival rates [8]. In saliva, the miRNAs (miR-10b*, miR-144 and miR-451) were identified up-regulated expression in EC, which possessed discriminatory ability of detecting EC [9]. Although these biomarkers contribute to the early diagnosis and prognosis of EC, the EC biomarker is still in the stage of exploration and verification, with limitations of specificity and low sensitivity.

Proteomic technologies have been applied to understand tumor pathogenesis, and to discover novel targets for cancer therapy or prognosis. Combining MS-based proteomic data with integrative bioinformatics can predict protein signal network and identify more clinical relevant molecules [10-12]. To date, quantitative proteomic methods have been applied in the study of various cancer, such as breast cancer, lung cancer, pancreatic cancer and gastric cancer [13]. Mass spectrometric identification of differentially expressed proteins has been a highly successful approach for finding novel cancer-specific biomarkers [14]. For more than a decade, attempts have been made to uncover valid biomarkers for the diagnosis of EC. Currently, various molecules have been identified as closely correlated with ESCC, such as transgelin (TAGLN) and proteasome activator 28-beta subunit (PA28 $\beta$ ) [15], pituitary tumor transforming gene (PTTG) [6], transglutaminase 3 (TGM) by proteomics [2]. However, the number of proteins identified was limited in these studies and they did not provide validation of the suggested biomarkers. Therefore, it is still necessary to perform further in-depth proteomics to explore novel candidate biomarkers for EC, and to validate the findings with orthogonal techniques.

Differential proteins obtained from mass spectrometry are commonly identified by Western Blot. However, it couldn't meet the requirements for high-throughput analysis, due to the complicated processing steps and the requirements for large amount of total protein. Recently, Quantitative Dot Blot (QDB) technology developed by our team achieves high-throughput quantitative detection with the same principle of traditional Western Blot. In addition, QDB technology has the advantages of less sample consumption, short time consumption and low cost [16]. The experiment has been successfully applied to the detection of biomarker of papillary thyroid carcinoma. With its accuracy and reliability, the QDB is a very effective method for protein detection.

The aim of this study was to investigate the protein expression profiles in ESCC tissues and adjacent normal esophageal tissues with a label-free quantitative proteomics approach through nano-liquid chromatography coupled with tandem mass spectrometry (Nano-LC-MS/ MS). The differentially expressed proteins were selected and their expression trends were validated in ESCC by Western Blot, then high-throughput protein screening was achieved by QDB, and the results of QDB were verified by classical IHC experiment. This research provides a new methodological strategy for validation and identification ESCC biomarkers by combining quantitative proteomic with QDB.

\section{Materials and methods Tissue samples}

The five patients for LC/MS analysis were all male, with the average age of 61. Samples of ESCC tissues and adjacent normal esophageal tissues were taken for mass spectrometry analysis. The 64 pairs of matched ESCC and adjacent normal tissue samples for QDB were based on a clear pathological diagnosis, which included 35 men and 29 women, with an age range of 46-73 years (mean 61 years). The above samples were obtained at the Affiliated Yantai Hospital of Binzhou Medical University. All data were obtained from patient medical records. All specimens were quickly rinsed and then frozen immediately in liquid nitrogen and then stored at $-80{ }^{\circ} \mathrm{C}$ until further processing. The tissue microarrays (TMA) (ES701 and ES1922) for immunohistochemistry analysis were purchased from the alenabio company, the total sample size reached 117 pairs after removing duplicates in two arrays $(n=14)$. This study was approved by the Human Research Ethics Committee of Binzhou Medical University. 
Table 1 The clinical features of ESCC patients for mass spectrometry

\begin{tabular}{llllll}
\hline No. & Gender & Age & Organ/anatomic site & Grade & TNM \\
\hline 1 & Male & 69 & Mid-thoracic esophagus & $\|$ & T2NOMO \\
2 & Male & 61 & esophagus & । & T1NOMO \\
3 & Male & 59 & Middle-lower esophagus & $\|$ & T1NOMO \\
4 & Male & 52 & Mid-thoracic esophagus & III & T3NOM0 \\
5 & Male & 64 & Middle segment of esophagus & $\|$ & T2N1M1 \\
\hline
\end{tabular}

\section{Reagents}

Rabbit anti-PPP1CA (CSB-PA030161) and rabbit antiPAK2 (CSB-PA622641DSR1HU) were purchased from CUSABIO (Wuhan, China). Rabbit anti-PTMA (YN2871) and rabbit anti-HMGB-2 (YT2187) were purchased from ImmunoWay Biotechnology Company (USA). The antibody of Caveolin (AF0126), Integrin beta-1 (AF5379), Collagen alpha-2(VI) (DF3552), Leiomodin-1 (DF12160) and Vinculin (AF5122) were purchased from Affinity Biosciences (USA). Mouse anti-GAPDH monoclonal antibody (sc-32233) was purchased from Santa Cruz Biotechnology (Dallas, TX, USA). Goat anti-rabbit $(127,760)$ and goat anti-mouse $(124,227)$ secondary antibodies were purchased from ZSGB-BIO (Beijing, China).

\section{Sample preparation}

The 5 pairs of clinical samples were homogenized and broken with lysis buffer containing $9 \mathrm{M}$ Urea, $20 \mathrm{mM}$ HEPES, and protease inhibitor cocktail. The samples were centrifuged at $12,000 \times g$ for $10 \mathrm{~min}$ at $4{ }^{\circ} \mathrm{C}$ and supernatants retained. Then $20 \mu \mathrm{g}$ of total protein were digested using the way of in-solution digestion. Firstly, the samples were reduced with $50 \mathrm{mM}$ dithiothreitol (DTT) at $50{ }^{\circ} \mathrm{C}$ for $15 \mathrm{~min}$, then alkylated with $50 \mathrm{mM}$ iodoacetamide (IAA) for $15 \mathrm{~min}$ in darkness, and then diluted 4 times with digestion buffer $\left(50 \mathrm{mM} \mathrm{NH}_{4} \mathrm{HCO}_{3}\right.$, $\mathrm{pH}$ 8.0). The proteins were digested by Trypsin with a final concentration of $5 \%(\mathrm{w} / \mathrm{w})$, then incubated at $37{ }^{\circ} \mathrm{C}$ overnight. The reaction was stopped by diluting the sample 1:1 with trifluoroacetic acid (TFA) in acetonitrile $(\mathrm{ACN})$ and Milli-Q water (1/5/94 v/v). Finally, peptides were desalted using Pierce C18 Spin Columns and dried completely in a vacuum centrifuge.

\section{LC-MS/MS}

The peptides were dissolved in $20 \mu \mathrm{L} 0.5 \%$ TFA in $5 \%$ ACN and analyzed using QExactive Plus Orbitrap ${ }^{\mathrm{TM}}$ mass spectrometer (Thermo Fisher Scientific, Bremen, Germany) coupled with the liquid chromatography system (EASY-nLC 1000, Thermo Fisher Scientific, Bremen, Germany). A 85-min LC gradient was applied, with a
Table 2 List of 102 proteins that were uniquely identified in ESCC tissues

\begin{tabular}{|c|c|}
\hline Protein IDs & Protein names \\
\hline P30050 & $60 S$ ribosomal protein $\mathrm{L} 12$ \\
\hline P25788 & Proteasome subunit alpha type-3 \\
\hline Q15254 & Prothymosin alpha \\
\hline P12956 & X-ray repair cross-complementing protein 6 \\
\hline 015371 & Eukaryotic translation initiation factor 3 subunit D \\
\hline Q59FF0 & Staphylococcal nuclease domain-containing protein 1 \\
\hline Q06323 & Proteasome activator complex subunit 1 \\
\hline Q15366 & Poly $(\mathrm{rC})$-binding protein 2;Poly $(\mathrm{rC})$-binding protein 3 \\
\hline Q99729 & Heterogeneous nuclear ribonucleoprotein A/B \\
\hline P62273 & $40 S$ ribosomal protein $\$ 29$ \\
\hline 015144 & Actin-related protein $2 / 3$ complex subunit 2 \\
\hline Q07955 & Serine/arginine-rich splicing factor 1 \\
\hline Q13838 & Spliceosome RNA helicase DDX39B \\
\hline Q14666 & Keratin, type I cytoskeletal 17 \\
\hline P00491 & Purine nucleoside phosphorylase \\
\hline P13667 & Protein disulfide-isomerase A4 \\
\hline P49755 & Transmembrane emp24 domain-containing protein 10 \\
\hline P34932 & Heat shock 70 kDa protein 4 \\
\hline P62750 & $60 S$ ribosomal protein L23a \\
\hline Q9BRL6 & Serine/arginine-rich splicing factor 2 \\
\hline P26583 & High mobility group protein B2 \\
\hline 060716 & Catenin delta-1 \\
\hline Q13151 & Heterogeneous nuclear ribonucleoprotein A0 \\
\hline P62244 & $40 \mathrm{~S}$ ribosomal protein S15a \\
\hline Q8TBK5 & $60 S$ ribosomal protein $L 6$ \\
\hline P39656 & $\begin{array}{l}\text { Dolichyl-diphosphooligosaccharide-protein glycosyltrans- } \\
\text { ferase } 48 \text { kDa subunit }\end{array}$ \\
\hline Q53GA7 & Tubulin alpha-1C chain \\
\hline Q92598 & Heat shock protein $105 \mathrm{kDa}$ \\
\hline Q92928 & Ras-related protein Rab-1B \\
\hline Q59F66 & Probable ATP-dependent RNA helicase DDX17 \\
\hline P46782 & 40 S ribosomal protein $\$ 5$ \\
\hline P78417 & Glutathione S-transferase omega-1 \\
\hline P23526 & Adenosylhomocysteinase \\
\hline P62081 & $40 S$ ribosomal protein $\mathrm{S} 7$ \\
\hline P11413 & Glucose-6-phosphate 1-dehydrogenase \\
\hline P67809 & Nuclease-sensitive element-binding protein 1 \\
\hline Q08211 & ATP-dependent RNA helicase A \\
\hline P17980 & 265 protease regulatory subunit $6 \mathrm{~A}$ \\
\hline Q59EG8 & 265 proteasome non-ATPase regulatory subunit 2 \\
\hline P27695 & DNA-(apurinic or apyrimidinic site) lyase, mitochondrial \\
\hline P61019 & Ras-related protein Rab-2A \\
\hline P28066 & Proteasome subunit alpha type \\
\hline P49588 & Alanine-tRNA ligase, cytoplasmic \\
\hline 014818 & Proteasome subunit alpha type \\
\hline Q8NB80 & Serine/arginine-rich splicing factor 7 \\
\hline Q86UE4 & Protein LYRIC \\
\hline P83731 & $60 S$ ribosomal protein $L 24$ \\
\hline B4DDM6 & Mitotic checkpoint protein BUB3 \\
\hline
\end{tabular}


Table 2 (continued)

\begin{tabular}{|c|c|}
\hline Protein IDs & Protein names \\
\hline P20618 & Proteasome subunit beta type \\
\hline P31942 & Heterogeneous nuclear ribonucleoprotein $\mathrm{H} 3$ \\
\hline Q13177 & Serine/threonine-protein kinase PAK 2 \\
\hline P53621 & Coatomer subunit alpha;Xenin;Proxenin \\
\hline Q04760 & Lactoylglutathione lyase \\
\hline Q99439 & Calponin;Calponin-2 \\
\hline P62266 & $40 S$ ribosomal protein $\mathrm{S} 23$ \\
\hline P62857 & $40 S$ ribosomal protein $\mathrm{S} 28$ \\
\hline O43852 & Calumenin \\
\hline Q567R6 & Single-stranded DNA-binding protein \\
\hline P22234 & Multifunctional protein ADE2 \\
\hline P62195 & 265 protease regulatory subunit 8 \\
\hline P98179 & RNA-binding protein 3 \\
\hline P46781 & 405 ribosomal protein 59 \\
\hline Q96FW1 & Ubiquitin thioesterase OTUB1 \\
\hline O14979 & Heterogeneous nuclear ribonucleoprotein D-like \\
\hline P51571 & Translocon-associated protein subunit delta \\
\hline P05455 & Lupus La protein \\
\hline Q96AE4 & Far upstream element-binding protein 1 \\
\hline P17844 & Probable ATP-dependent RNA helicase DDX5 \\
\hline P52597 & Heterogeneous nuclear ribonucleoprotein F \\
\hline P60866 & $40 S$ ribosomal protein $\mathrm{S} 20$ \\
\hline Q13148 & TAR DNA-binding protein 43 \\
\hline P62136 & $\begin{array}{l}\text { Serine/threonine-protein phosphatase PP1-alpha catalytic } \\
\text { subunit }\end{array}$ \\
\hline P07602 & Prosaposin \\
\hline P62633 & Cellular nucleic acid-binding protein \\
\hline Q6FI03 & Ras GTPase-activating protein-binding protein 1 \\
\hline P51572 & B-cell receptor-associated protein 31 \\
\hline P27635 & $60 S$ ribosomal protein L10 \\
\hline Q09028 & Histone-binding protein RBBP4 \\
\hline Q9UMS4 & Pre-mRNA-processing factor 19 \\
\hline P62318 & Small nuclear ribonucleoprotein Sm D3 \\
\hline Q15056 & Eukaryotic translation initiation factor $4 \mathrm{H}$ \\
\hline P38159 & RNA-binding motif protein, $\mathrm{X}$ chromosome \\
\hline Q1KMD3 & Heterogeneous nuclear ribonucleoprotein U-like protein 2 \\
\hline P17987 & T-complex protein 1 subunit alpha \\
\hline Q13263 & Transcription intermediary factor 1-beta \\
\hline P29590 & Protein PML \\
\hline Q92499 & ATP-dependent RNA helicase DDX1 \\
\hline P51858 & Hepatoma-derived growth factor \\
\hline P60468 & Protein transport protein Sec61 subunit beta \\
\hline Q13185 & Chromobox protein homolog 3 \\
\hline P55209 & Nucleosome assembly protein 1-like 1 \\
\hline P50454 & Serpin $\mathrm{H} 1$ \\
\hline P42704 & Leucine-rich PPR motif-containing protein, mitochondrial \\
\hline P61204 & ADP-ribosylation factor 1;ADP-ribosylation factor 3 \\
\hline Q9HB71 & Calcyclin-binding protein \\
\hline P11166 & $\begin{array}{l}\text { Solute carrier family } 2 \text {, facilitated glucose transporter } \\
\text { member } 1\end{array}$ \\
\hline
\end{tabular}

Table 2 (continued)

\begin{tabular}{ll}
\hline Protein IDs & Protein names \\
\hline Q9Y265 & RuvB-like 1 \\
P62807 & Histone H2B \\
Q94K76 & Hematological and neurological expressed 1 protein \\
P12004 & Proliferating cell nuclear antigen \\
P43243 & Matrin-3 \\
P62333 & 26S protease regulatory subunit 10B \\
\hline
\end{tabular}

binary mobile phase system of buffer A $(0.1 \%$ formic acid) and buffer B (80\% acetonitrile with $0.1 \%$ formic acid) at a flow rate of $250 \mathrm{~nL} / \mathrm{min}$. In MS analysis, peptides were loaded onto the $2 \mathrm{~cm}$ EASY-column precolumn (1D $100 \mu \mathrm{m}, 5 \mu \mathrm{m}, \mathrm{C} 18$, Thermo Fisher Scientific), and eluted at a $10 \mathrm{~cm}$ EASY-column analytical column (1D $75 \mu \mathrm{m}, 3 \mu \mathrm{m}, \mathrm{C} 18$, Thermo Fisher Scientific). For information data dependent analysis (DDA), full scan MS spectra were executed in the $\mathrm{m} / \mathrm{z}$ range $150-2000$ at a resolution of 70,000. The peptides elution was performed with a linear gradient from 4 to $100 \% \mathrm{ACN}$ at the speed $250 \mathrm{~nL} / \mathrm{min}$ in $90 \mathrm{~min}$. Then the top 10 precursors were dissociated into fragmentation spectra by high collision dissociation (HCD) in positive ion mode.

\section{Proteomic data processing}

The acquired data were analyzed by using Maxquant (version 1.5.0.1) against the UniProt Homo sapiens database. The searching parameters were set as maximum 10 and $5 \mathrm{ppm}$ error tolerance for the survey scan and MS/ MS analysis, respectively. The enzyme was trypsin, and two missed cuts were allowed. The max number of modifications per peptide is 5 . Using the Label-free quantification (LFQ), the LFQ minimum ratio count was set to 2. The FDR (false discovery rate) was set to $1 \%$ for the peptide spectrum matches (PSMs) and protein quantitation. Gene ontology and protein class analysis were performed with the PANTHER system (http://pantherdb. org/). Meanwhile, the heat map of significantly different proteins was screened by using Morpheus (https://softw are.broadinstitute.org/morpheus). The protein-protein interaction analysis of the differently expressed proteins was performed by STRING (https://string-db.org/).

\section{Western blot (WB)}

Tissues lysates were prepared by using highly efficient RIPA lysis buffer including PMSF (Phenylmethanesulfonyl fluoride). The total proteins were quantified by BCA protein assay kit and then separated by sodium dodesyl sulphate-polyacrylamide gel electrophoresis (SDSPAGE). Equal amounts of protein were separated by $6 \%$, $15 \%$ and $12 \%$ SDS-PAGE, respectively. Subsequently, 
Table 3 List of 155 proteins that were overexpressed in ESCC tissues

\begin{tabular}{|c|c|c|c|}
\hline IDs & Log ratio & $P$ value & Protein names \\
\hline P60842 & 7.814 & 0.000 & Eukaryotic initiation factor 4A-I \\
\hline P23396 & 6.277 & 0.000 & $40 S$ ribosomal protein $\$ 3$ \\
\hline P52272 & 7.623 & 0.000 & $\begin{array}{l}\text { Heterogeneous nuclear ribonucleo- } \\
\text { protein M }\end{array}$ \\
\hline P43686 & 10.195 & 0.000 & 265 protease regulatory subunit $6 \mathrm{~B}$ \\
\hline P14866 & 8.871 & 0.000 & $\begin{array}{l}\text { Heterogeneous nuclear ribonucleo- } \\
\text { protein } L\end{array}$ \\
\hline P53675 & 5.484 & 0.001 & $\begin{array}{l}\text { Clathrin heavy chain;Clathrin heavy } \\
\text { chain } 1\end{array}$ \\
\hline P84090 & 11.171 & 0.001 & Enhancer of rudimentary homolog \\
\hline P22392 & 12.881 & 0.001 & Nucleoside diphosphate kinase \\
\hline Q01105 & 7.330 & 0.001 & Protein SET;Protein SETSIP \\
\hline P84103 & 7.084 & 0.001 & Serine/arginine-rich splicing factor 3 \\
\hline P07900 & 9.462 & 0.001 & Heat shock protein HSP 90-alpha \\
\hline Q01518 & 2.076 & 0.001 & Adenylyl cyclase-associated protein \\
\hline Q15233 & 22.489 & 0.001 & $\begin{array}{l}\text { Non-POU domain-containing octamer- } \\
\text { binding protein }\end{array}$ \\
\hline P51149 & 7.249 & 0.001 & Ras-related protein Rab-7a \\
\hline Q05CK9 & 9.797 & 0.001 & $\begin{array}{l}\text { Heterogeneous nuclear ribonucleo- } \\
\text { protein Q }\end{array}$ \\
\hline P10809 & 9.235 & 0.001 & $\begin{array}{l}60 \mathrm{kDa} \text { heat shock protein, mitochon- } \\
\text { drial }\end{array}$ \\
\hline P68371 & 1.935 & 0.001 & Tubulin beta- $4 \mathrm{~B}$ chain \\
\hline P37802 & 3.333 & 0.001 & Transgelin-2 \\
\hline P62826 & 6.962 & 0.002 & GTP-binding nuclear protein Ran \\
\hline P25398 & 4.816 & 0.002 & $40 S$ ribosomal protein $\mathrm{S} 12$ \\
\hline P57723 & 4.611 & 0.002 & Poly(rC)-binding protein 1 \\
\hline Q12906 & 28.577 & 0.002 & Interleukin enhancer-binding factor 3 \\
\hline P08865 & 5.309 & 0.002 & 40 S ribosomal protein SA \\
\hline P63244 & 6.237 & 0.002 & $\begin{array}{l}\text { Guanine nucleotide-binding protein } \\
\text { subunit beta-2-like } 1\end{array}$ \\
\hline P14314 & 14.510 & 0.002 & Glucosidase 2 subunit beta \\
\hline P60900 & 9.105 & 0.002 & Proteasome subunit alpha type \\
\hline P06748 & 12.711 & 0.002 & Nucleophosmin \\
\hline P05388 & 8.012 & 0.002 & 605 acidic ribosomal protein P0 \\
\hline P46940 & 3.595 & 0.003 & $\begin{array}{l}\text { Ras GTPase-activating-like protein } \\
\text { IQGAP1 }\end{array}$ \\
\hline P61978 & 10.444 & 0.003 & $\begin{array}{l}\text { Heterogeneous nuclear ribonucleo- } \\
\text { protein } \mathrm{K}\end{array}$ \\
\hline P05141 & 2.807 & 0.003 & ADP/ATP translocase 2 \\
\hline Q6LDX7 & 13.007 & 0.003 & Tyrosine-protein kinase receptor \\
\hline Q99623 & 14.381 & 0.003 & Prohibitin-2 \\
\hline P06733 & 2.361 & 0.003 & Alpha-enolase \\
\hline P13639 & 5.459 & 0.003 & Elongation factor 2 \\
\hline Q15084 & 43.388 & 0.003 & Protein disulfide-isomerase A6 \\
\hline Q96DV6 & 3.944 & 0.003 & 405 ribosomal protein 56 \\
\hline Q66K53 & 9.606 & 0.003 & HNRPA3 protein \\
\hline P15880 & 4.502 & 0.003 & $40 S$ ribosomal protein $\$ 2$ \\
\hline P39019 & 5.898 & 0.004 & $40 S$ ribosomal protein S19 \\
\hline P63104 & 2.043 & 0.004 & 14-3-3 protein zeta/delta \\
\hline
\end{tabular}

Table 3 (continued)

\begin{tabular}{|c|c|c|c|}
\hline IDs & Log ratio & $P$ value & Protein names \\
\hline P22626 & 6.638 & 0.004 & $\begin{array}{l}\text { Heterogeneous nuclear ribonucleopro- } \\
\text { teins A2/B1 }\end{array}$ \\
\hline P30101 & 6.086 & 0.005 & Protein disulfide-isomerase \\
\hline P25786 & 8.420 & 0.005 & Proteasome subunit alpha type-1 \\
\hline P11940 & 12.404 & 0.006 & Polyadenylate-binding protein \\
\hline P16401 & 4.877 & 0.006 & Histone H1.5 \\
\hline P07237 & 5.704 & 0.006 & Protein disulfide-isomerase \\
\hline Q16777 & 10.160 & 0.006 & $\begin{array}{l}\text { Histone } \mathrm{H} 2 \mathrm{~A} \text { type 2-C;Histone H2A } \\
\text { type 2-A }\end{array}$ \\
\hline P05386 & 5.889 & 0.006 & $60 S$ acidic ribosomal protein P1 \\
\hline P31948 & 11.491 & 0.006 & Stress-induced-phosphoprotein 1 \\
\hline P31946 & 2.156 & 0.007 & 14-3-3 protein beta/alpha \\
\hline P68104 & 2.558 & 0.007 & Elongation factor 1-alpha \\
\hline P00338 & 1.590 & 0.007 & L-lactate dehydrogenase \\
\hline Q14103 & 6.189 & 0.007 & $\begin{array}{l}\text { Heterogeneous nuclear ribonucleo- } \\
\text { protein D0 }\end{array}$ \\
\hline P38646 & 10.649 & 0.007 & Stress-70 protein, mitochondrial \\
\hline P26641 & 19.766 & 0.007 & Elongation factor 1-gamma \\
\hline 075347 & 4.168 & 0.008 & Tubulin-specific chaperone A \\
\hline P09429 & 5.878 & 0.008 & High mobility group protein B1 \\
\hline P62942 & 7.427 & 0.008 & $\begin{array}{l}\text { Peptidyl-prolyl cis-trans isomerase } \\
\text { FKBP1A }\end{array}$ \\
\hline Q9NUV1 & 7.289 & 0.008 & Cytosolic non-specific dipeptidase \\
\hline P11021 & 7.467 & 0.008 & 78 kDa glucose-regulated protein \\
\hline P11142 & 2.320 & 0.008 & Heat shock cognate $71 \mathrm{kDa}$ protein \\
\hline P02533 & 5.320 & 0.008 & Keratin, type I cytoskeletal 14 \\
\hline P30040 & 6.657 & 0.008 & $\begin{array}{l}\text { Endoplasmic reticulum resident } \\
\text { protein } 29\end{array}$ \\
\hline P50990 & 11.713 & 0.008 & T-complex protein 1 subunit theta \\
\hline P46783 & 9.508 & 0.008 & $40 S$ ribosomal protein $\$ 10$ \\
\hline P31943 & 14.091 & 0.008 & $\begin{array}{l}\text { Heterogeneous nuclear ribonucleo- } \\
\text { protein } \mathrm{H}\end{array}$ \\
\hline P19338 & 13.679 & 0.009 & Nucleolin \\
\hline P14625 & 13.173 & 0.009 & Endoplasmin \\
\hline Q92597 & 4.464 & 0.009 & Protein NDRG1 \\
\hline P26599 & 19.501 & 0.009 & Polypyrimidine tract-binding protein 1 \\
\hline P68363 & 2.317 & 0.009 & Tubulin alpha-1B chain \\
\hline P61604 & 9.723 & 0.009 & $\begin{array}{l}10 \text { kDa heat shock protein, mitochon- } \\
\text { drial }\end{array}$ \\
\hline P08238 & 8.920 & 0.009 & Heat shock protein HSP 90-beta \\
\hline Q00839 & 15.338 & 0.009 & $\begin{array}{l}\text { Heterogeneous nuclear ribonucleo- } \\
\text { protein } U\end{array}$ \\
\hline P04843 & 64.275 & 0.009 & $\begin{array}{l}\text { Dolichyl-diphosphooligosaccharide-- } \\
\text { protein glycosyltransferase subunit } 1\end{array}$ \\
\hline P09651 & 10.489 & 0.010 & $\begin{array}{l}\text { Heterogeneous nuclear ribonucleo- } \\
\text { protein A1 }\end{array}$ \\
\hline P22314 & 3.758 & 0.010 & $\begin{array}{l}\text { Ubiquitin-like modifier-activating } \\
\text { enzyme } 1\end{array}$ \\
\hline P30085 & 3.180 & 0.010 & UMP-CMP kinase \\
\hline P23246 & 39.026 & 0.011 & $\begin{array}{l}\text { Splicing factor, proline- and glutamine- } \\
\text { rich }\end{array}$ \\
\hline P29692 & 13.726 & 0.011 & Elongation factor 1-delta \\
\hline
\end{tabular}


Table 3 (continued)

\begin{tabular}{|c|c|c|c|}
\hline IDs & Log ratio & $P$ value & Protein names \\
\hline P27797 & 7.508 & 0.011 & Calreticulin \\
\hline Q06830 & 1.788 & 0.011 & Peroxiredoxin-1 \\
\hline P84243 & 2.541 & 0.012 & Histone H3 \\
\hline P05023 & 15.342 & 0.012 & $\begin{array}{l}\text { Sodium/potassium-transporting } \\
\text { ATPase subunit alpha-1 }\end{array}$ \\
\hline Q14974 & 3.995 & 0.014 & Importin subunit beta-1 \\
\hline P30154 & 2.882 & 0.014 & $\begin{array}{l}\text { Serine/threonine-protein phosphatase } \\
\text { 2A }\end{array}$ \\
\hline P49448 & 5.013 & 0.015 & Glutamate dehydrogenase \\
\hline P20700 & 14.379 & 0.015 & Lamin-B1 \\
\hline P55072 & 6.054 & 0.016 & $\begin{array}{l}\text { Transitional endoplasmic reticulum } \\
\text { ATPase }\end{array}$ \\
\hline P35579 & 8.278 & 0.016 & Myosin-9 \\
\hline P40227 & 8.241 & 0.016 & T-complex protein 1 subunit zeta \\
\hline P13010 & 223.628 & 0.017 & $\begin{array}{l}\text { X-ray repair cross-complementing } \\
\text { protein } 5\end{array}$ \\
\hline Q03252 & 12.919 & 0.017 & Lamin-B2 \\
\hline P27824 & 9.105 & 0.017 & Calnexin \\
\hline P02545 & 1.376 & 0.017 & Prelamin-A/C;Lamin-A/C \\
\hline P67936 & 10.102 & 0.017 & Tropomyosin alpha-4 chain \\
\hline P04908 & 2.018 & 0.018 & Histone $\mathrm{H} 2 \mathrm{~A}$ \\
\hline P13797 & 5.684 & 0.019 & Plastin-3 \\
\hline P52907 & 3.377 & 0.019 & $\begin{array}{l}\text { F-actin-capping protein subunit } \\
\text { alpha-1 }\end{array}$ \\
\hline P63241 & 4.197 & 0.019 & $\begin{array}{l}\text { Eukaryotic translation initiation factor } \\
5 \mathrm{~A}\end{array}$ \\
\hline P62491 & 3.628 & 0.019 & $\begin{array}{l}\text { Ras-related protein Rab-11A;Ras- } \\
\text { related protein Rab-11B }\end{array}$ \\
\hline P45880 & 2.304 & 0.020 & $\begin{array}{l}\text { Voltage-dependent anion-selective } \\
\text { channel protein } 2\end{array}$ \\
\hline P05387 & 4.257 & 0.020 & 605 acidic ribosomal protein P2 \\
\hline Q5SRT3 & 3.484 & 0.021 & Chloride intracellular channel protein \\
\hline P07437 & 3.687 & 0.021 & Tubulin beta chain \\
\hline P23284 & 8.401 & 0.022 & Peptidyl-prolyl cis-trans isomerase \\
\hline P18124 & 5.442 & 0.022 & 605 ribosomal protein $L 7$ \\
\hline P07355 & 1.909 & 0.022 & Annexin;Annexin A2 \\
\hline P46777 & 12.124 & 0.023 & $60 S$ ribosomal protein L5 \\
\hline Q99714 & 1.923 & 0.023 & $\begin{array}{l}\text { 3-hydroxyacyl-CoA dehydrogenase } \\
\text { type-2 }\end{array}$ \\
\hline 075531 & 9.745 & 0.024 & Barrier-to-autointegration factor \\
\hline Q14697 & 21.165 & 0.025 & Neutral alpha-glucosidase AB \\
\hline P62263 & 6.347 & 0.025 & $40 S$ ribosomal protein $\mathrm{S} 14$ \\
\hline PODMV9 & 2.049 & 0.026 & Heat shock 70 kDa protein 1B \\
\hline P29034 & 6.458 & 0.026 & Protein S100-A2 \\
\hline P62888 & 2.893 & 0.026 & $60 S$ ribosomal protein L30 \\
\hline Q6IBT3 & 23.335 & 0.027 & T-complex protein 1 subunit eta \\
\hline P47756 & 2.818 & 0.027 & F-actin-capping protein subunit beta \\
\hline P35222 & 7.555 & 0.028 & Catenin beta-1 \\
\hline P07339 & 5.983 & 0.029 & Cathepsin D \\
\hline Q86SZ7 & 4.151 & 0.029 & $\begin{array}{l}\text { Proteasome activator complex subunit } \\
\quad 2\end{array}$ \\
\hline P15311 & 3.903 & 0.029 & Ezrin;Tyrosine-protein kinase receptor \\
\hline
\end{tabular}

Table 3 (continued)

\begin{tabular}{|c|c|c|c|}
\hline IDs & Log ratio & $P$ value & Protein names \\
\hline P59665 & 4.537 & 0.029 & Neutrophil defensin 1 \\
\hline P09960 & 5.492 & 0.030 & Leukotriene A-4 hydrolase \\
\hline P63220 & 4.048 & 0.030 & $40 S$ ribosomal protein $\$ 21$ \\
\hline Q16658 & 114.974 & 0.031 & Fascin \\
\hline P07954 & 5.399 & 0.032 & Fumarate hydratase, mitochondrial \\
\hline P54819 & 4.652 & 0.034 & Adenylate kinase 2, mitochondrial \\
\hline P07737 & 1.223 & 0.034 & Profilin-1 \\
\hline P63313 & 5.261 & 0.034 & Thymosin beta-10 \\
\hline P21796 & 3.716 & 0.034 & $\begin{array}{l}\text { Voltage-dependent anion-selective } \\
\text { channel protein } 1\end{array}$ \\
\hline P61247 & 12.449 & 0.035 & 405 ribosomal protein S3a \\
\hline P14618 & 1.508 & 0.035 & Pyruvate kinase \\
\hline P61626 & 4.029 & 0.036 & Lysozyme;Lysozyme C \\
\hline Q15181 & 8.459 & 0.037 & Inorganic pyrophosphatase \\
\hline P27348 & 3.220 & 0.037 & 14-3-3 protein theta \\
\hline P49411 & 14.069 & 0.037 & Elongation factor Tu, mitochondrial \\
\hline P05164 & 10.019 & 0.037 & Myeloperoxidase \\
\hline P61160 & 5.976 & 0.038 & Actin-related protein 2 \\
\hline Q04917 & 4.768 & 0.039 & 14-3-3 protein eta \\
\hline P62805 & 1.761 & 0.039 & Histone H4 \\
\hline P26373 & 3.700 & 0.040 & 605 ribosomal protein $\mathrm{L} 13$ \\
\hline Q14204 & 2.799 & 0.041 & Cytoplasmic dynein 1 heavy chain 1 \\
\hline P56537 & 7.504 & 0.041 & Eukaryotic translation initiation factor 6 \\
\hline P08708 & 10.144 & 0.042 & 405 ribosomal protein $\mathrm{S} 17$ \\
\hline P15153 & 2.613 & 0.042 & $\begin{array}{l}\text { Ras-related C } 3 \text { botulinum toxin } \\
\text { substrate } 2\end{array}$ \\
\hline P31949 & 2.100 & 0.045 & Protein S100 \\
\hline P36952 & 6.679 & 0.046 & Serpin B5 \\
\hline Q15149 & 4.694 & 0.047 & Plectin \\
\hline P46779 & 6.182 & 0.048 & $60 S$ ribosomal protein $\mathrm{L} 28$ \\
\hline Q59FH0 & 5.442 & 0.048 & Histone $\mathrm{H} 2 \mathrm{~A}$ \\
\hline P62937 & 1.778 & 0.049 & Peptidyl-prolyl cis-trans isomerase \\
\hline P07741 & 5.077 & 0.049 & Adenine phosphoribosyltransferase \\
\hline P62269 & 3.688 & 0.050 & 405 ribosomal protein $\mathrm{S} 18$ \\
\hline
\end{tabular}

proteins were transferred to a PVDF membrane and then blocked with TBS (pH 7.4) containing $0.05 \%$ Tween 20 and $5 \%$ nonfat milk. Next, the membranes were incubated with rabbit anti-PTMA (1:1000), rabbit antiHMGB-2 (1:500), rabbit anti- PPP1CA (1:1000), rabbit anti-PAK2 (1:1000), and mouse anti-GAPDH (1:1000) antibodies at $4{ }^{\circ} \mathrm{C}$ overnight, respectively. The other five antibodies (Caveolin, Integrin beta-1, Collagen alpha2(VI), Leiomodin-1 and Vinculin) were diluted in a ratio of 1:200. After washing, membranes were incubated with goat anti-rabbit (1:2000) and goat anti-mouse (1:2000) secondary antibodies at room temperature for $1 \mathrm{~h}$. The ECL system was used to detect protein expression. 
Table 4 List of 40 proteins that were low-expressed in ESCC tissues

\begin{tabular}{|c|c|c|c|}
\hline IDs & Log ratio & $P$ value & Protein names \\
\hline P55268 & 0.078 & 0.001 & Laminin subunit beta-2 \\
\hline Q13361 & 0.000 & 0.001 & Microfibrillar-associated protein 5 \\
\hline O95682 & 0.000 & 0.001 & Tenascin-X \\
\hline P12277 & 0.024 & 0.001 & Creatine kinase B-type \\
\hline P20774 & 0.018 & 0.002 & Mimecan \\
\hline P06396 & 0.501 & 0.002 & Gelsolin \\
\hline O75106 & 0.000 & 0.002 & Membrane primary amine oxidase \\
\hline P60660 & 0.260 & 0.002 & Myosin light polypeptide 6 \\
\hline P51884 & 0.118 & 0.003 & Lumican \\
\hline P35555 & 0.183 & 0.003 & Fibrillin-1 \\
\hline Q5U0D2 & 0.081 & 0.004 & Transgelin \\
\hline P35749 & 0.029 & 0.004 & Myosin-11 \\
\hline P51888 & 0.032 & 0.004 & Prolargin \\
\hline P24844 & 0.033 & 0.005 & Myosin regulatory light polypeptide 9 \\
\hline P17661 & 0.063 & 0.005 & Desmin \\
\hline P98160 & 0.213 & 0.006 & $\begin{array}{l}\text { Basement membrane-specific heparan } \\
\text { sulfate proteoglycan core protein }\end{array}$ \\
\hline P12109 & 0.299 & 0.006 & Collagen alpha-1(VI) chain \\
\hline Q07507 & 0.084 & 0.006 & Dermatopontin \\
\hline P11047 & 0.209 & 0.006 & Laminin subunit gamma-1 \\
\hline Q6ZN40 & 0.114 & 0.006 & CDNA FLJ16459 fis \\
\hline P18206 & 0.259 & 0.008 & Vinculin \\
\hline Q14112 & 0.065 & 0.010 & Nidogen-2 \\
\hline P21291 & 0.086 & 0.011 & Cysteine and glycine-rich protein 1 \\
\hline P68032 & 0.312 & 0.011 & Actin, alpha cardiac muscle 1 \\
\hline Q9NZN4 & 0.000 & 0.012 & EH domain-containing protein 2 \\
\hline P07585 & 0.087 & 0.012 & Decorin \\
\hline Q15746 & 0.021 & 0.014 & $\begin{array}{l}\text { Myosin light chain kinase, smooth } \\
\text { muscle }\end{array}$ \\
\hline Q9Y490 & 0.318 & 0.015 & Talin-1 \\
\hline P12110 & 0.223 & 0.016 & Collagen alpha-2(VI) chain \\
\hline P21810 & 0.235 & 0.020 & Biglycan \\
\hline Q93052 & 0.048 & 0.021 & Lipoma-preferred partner \\
\hline P30086 & 0.507 & 0.021 & $\begin{array}{l}\text { Phosphatidylethanolamine-binding } \\
\text { protein } 1\end{array}$ \\
\hline P62736 & 0.043 & 0.022 & Actin, aortic smooth muscle \\
\hline Q96AC1 & 0.029 & 0.023 & Fermitin family homolog 2 \\
\hline Q6NZI2 & 0.213 & 0.025 & Polymerase I and transcript release factor \\
\hline Q59F18 & 0.000 & 0.027 & Smoothelin isoform b variant \\
\hline 014558 & 0.000 & 0.027 & Heat shock protein beta- 6 \\
\hline Q13642 & 0.004 & 0.028 & Four and a half LIM domains protein 1 \\
\hline P12111 & 0.321 & 0.031 & Collagen alpha-3(VI) chain \\
\hline P29536 & 0.000 & 0.032 & Leiomodin-1 \\
\hline P05556 & 0.416 & 0.033 & Integrin beta-1 \\
\hline Q15124 & 0.000 & 0.033 & Phosphoglucomutase-like protein 5 \\
\hline P21333 & 0.213 & 0.033 & Filamin-A \\
\hline Q53GG5 & 0.013 & 0.036 & PDZ and LIM domain protein 3 \\
\hline P01009 & 0.429 & 0.037 & $\begin{array}{l}\text { Alpha-1-antitrypsin;Short peptide from } \\
\text { AAT }\end{array}$ \\
\hline P43121 & 0.000 & 0.038 & Cell surface glycoprotein MUC18 \\
\hline
\end{tabular}

Table 4 (continued)

\begin{tabular}{llll}
\hline IDs & Log ratio & $\boldsymbol{P}$ value & Protein names \\
\hline P52943 & 0.210 & 0.041 & Cysteine-rich protein 2 \\
P08294 & 0.000 & 0.043 & $\begin{array}{c}\text { Extracellular superoxide dismutase } \\
{[\text { Cu-Zn }]}\end{array}$ \\
& & & Caveolin \\
P56539 & 0.155 & 0.043 & Synemin \\
O15061 & 0.000 & 0.045 & PDZ and LIM domain protein 7 \\
Q9NR12 & 0.044 & 0.047 & P
\end{tabular}

QDB

The total proteins were quantified by BCA protein assay kit and then validated by Quantitative Dot Blot (QDB). Firstly, we determined the linear range of PTMA of the QDB analysis, through the testing of series of concentrations including $0,0.25,0.5,1,2$ and $4 \mu \mathrm{g} / \mu \mathrm{L}$. After that, equal amounts of protein were loaded. The sample was incubated at $37{ }^{\circ} \mathrm{C}$ for $15 \mathrm{~min}$ or until the membrane was completely dried. To block the plate, the QDB plate was dipped in $20 \%$ methanol. The plate was then washed with TBST, followed by $5 \%$ fat-free milk under constant shaking at room temperature for $1 \mathrm{~h}$. After washing with TBST, the QDB plate was placed in a 96 well plate and $100 \mu \mathrm{L}$ of primary antibodies was separately added to each individual well and shaken overnight at $4{ }^{\circ} \mathrm{C}$. After washing the QDB plate, $100 \mu \mathrm{L}$ of the secondary antibody was added to each well and incubated for $1 \mathrm{~h}$ at room temperature with shaking. Samples were washed with TBST and detected with the ECL substrate using a Tecan Infiniti 200 pro microplate reader. For each sample, a triplicate measurement was performed, and the average value was obtained. The relative quantitation of each PTMA protein in the lysates was then calculated.

\section{Immunohistochemistry (IHC)}

The PTMA expression was detected by IHC in tissue microarrays (TMA) (ES701, ES1922). Firstly, the tissue microarrays were heated at $60{ }^{\circ} \mathrm{C}$ for $30 \mathrm{~min}$, then deparaffinized and hydrated with xylol and gradient alcohol, respectively. Next, the antigen retrieval was accomplished by boiling the TMAs for $10 \mathrm{~min}$ in citrate buffer $(0.01 \mathrm{M}$, $\mathrm{pH}$ 6.0). After cooling at room temperature, the microarrays were treated with $3 \%$ hydrogen peroxide for $30 \mathrm{~min}$ at $37^{\circ} \mathrm{C}$. The samples were blocked with bovine serum albumin for $30 \mathrm{~min}$ at $37{ }^{\circ} \mathrm{C}$, then the PTMA antibody (YN2871, ImmunoWay; dilution 1:50) were incubated overnight at $4{ }^{\circ} \mathrm{C}$ in a moist chamber. After using the Histostain-SP (Streptavidin-Peroxidase) kit (SP-0023) as the secondary antibody following the recommendation from the manufacture, operation manual, the samples were washed with PBS (0.01 M, pH 7.2-7.4). Finally, the 
a

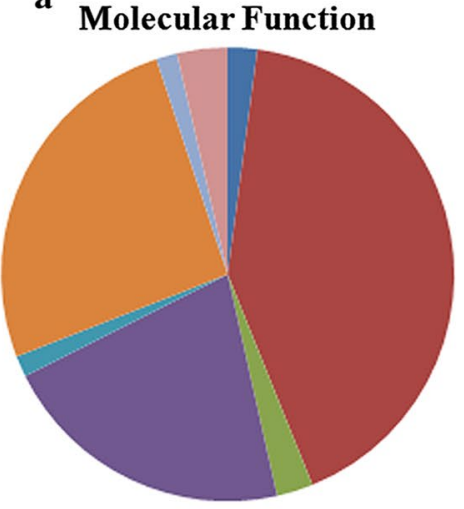

b

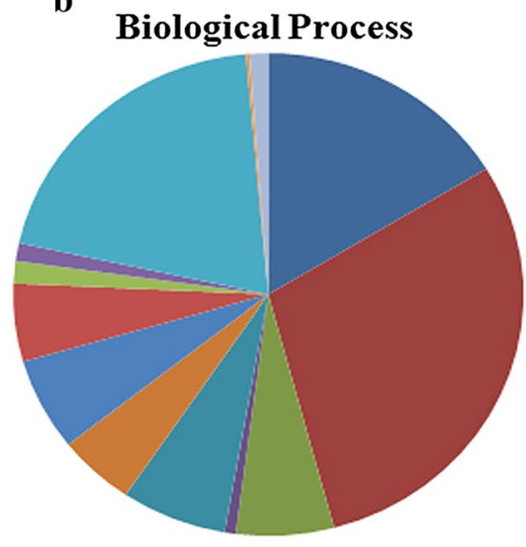

c

\section{Cellular Component}

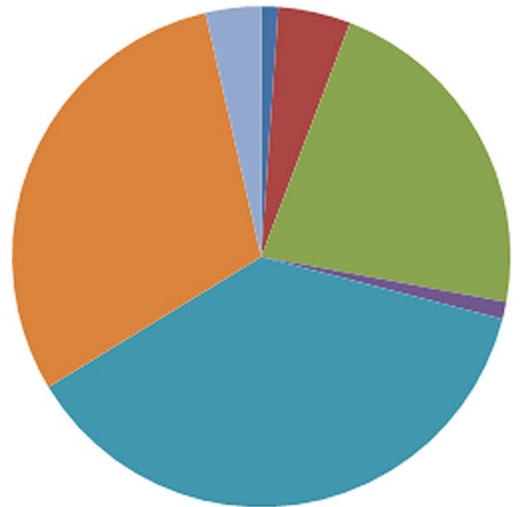

घ translation regulator activity (GO:0045182) $2.1 \%$

घbinding (GO:0005483) $41.8 \%$

receptor activity (GO:0004872) $2.6 \%$

$\square$ structural molecule activity (GO:0005198) $21.1 \%$

a signal transducer activity (GO:0004871) $1.5 \%$

$\square$ catalytic activity (GO:0003824) $25.8 \%$

$\square$ antioxidant activity (GO:0016209) $1.5 \%$

$\square$ transporter activity (GO:0005215) 3.6\%

- cellular component organization or biogenesis (GO:0071840) $16.3 \%$

a cellular process (GO:0009987) $29.6 \%$

- localization (GO:0051179) 6.2\%

n reproduction (GO:0000003) $0.7 \%$

abiological regulation (GO:0065007) 6.7\%

response to stimulus (GO:0050896) $4.9 \%$

$\square$ developmental process (GO:0032502) $6.2 \%$

$\square$ multicellular organismal process (GO:0032501) $5.2 \%$

$\square$ locomotion (GO:0040011) $1.5 \%$

Fig. 1 Classification of identified proteins by gene ontology based on their a molecular function, $\mathbf{b}$ biological process and $\mathbf{c}$ cellular component. The analysis of proteins were performed via the PANTHER (http://pantherdb.org/) 


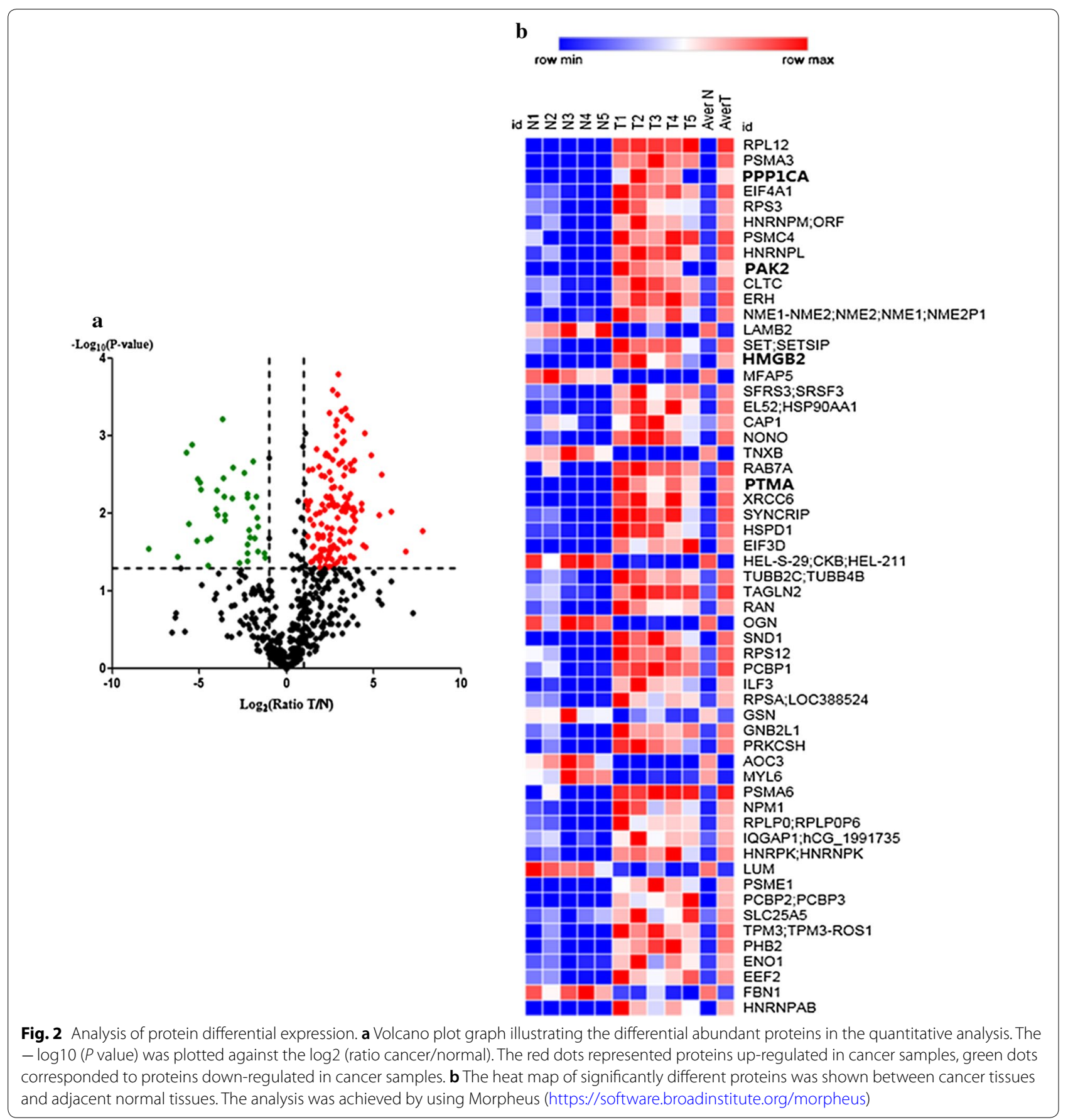

immunoreactivity was detected by DAB Horseradish Peroxidase Color Development Kit.

\section{Statistics analysis}

The WB data was analyzed by means and standard deviation for four independent experiments. The other data was compared between esophageal cancer tissues and adjacent normal esophageal tissues using the two-tailed paired Student's $t$ test. All statistical analyses were performed by using the statistical software SPSS v20.0 (Chicago, Illinois, USA). $P<0.05$ was considered statistically significant. 


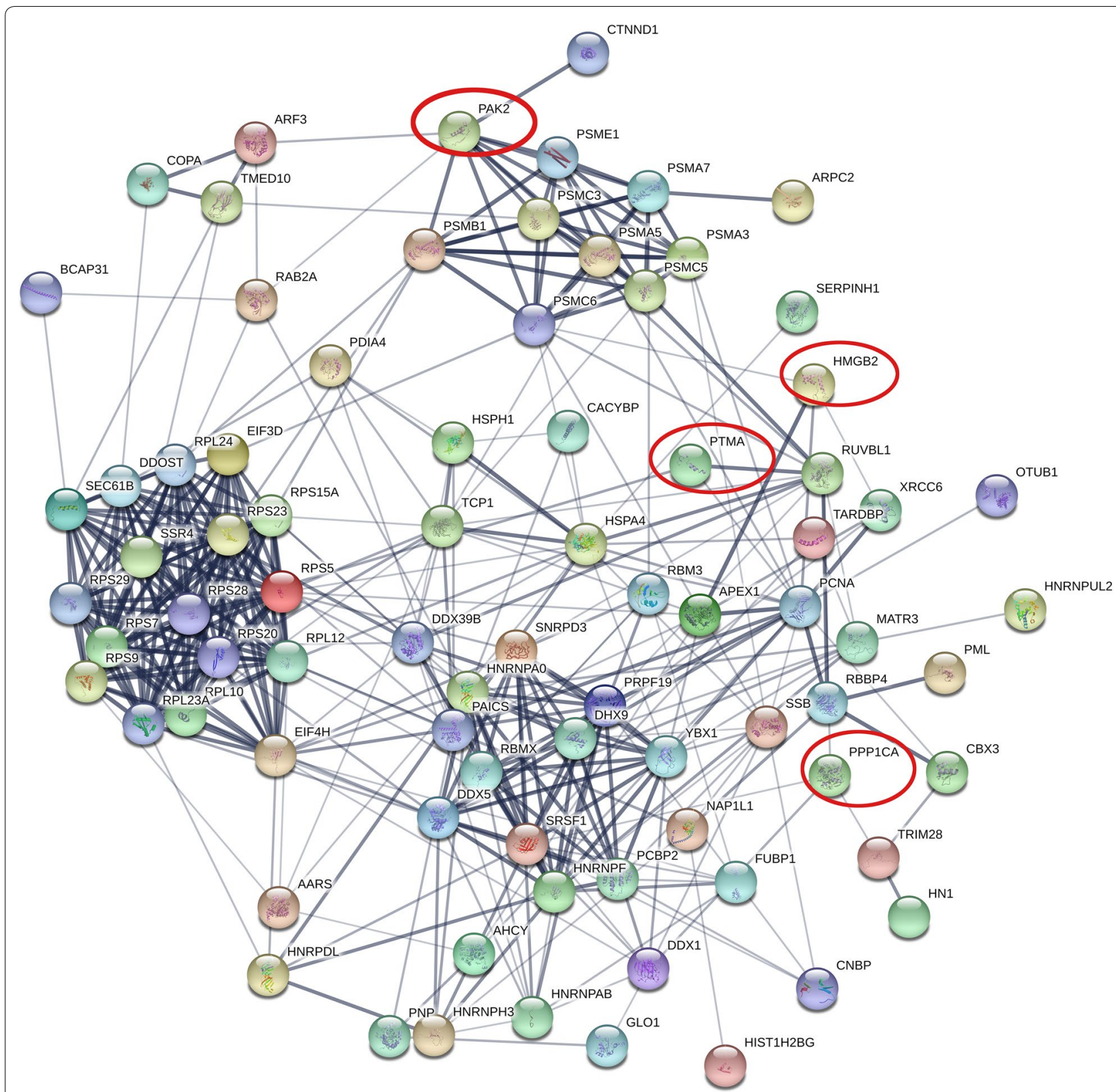

Fig. 3 Protein-protein interaction network of the differently expressed proteins was identified by STRING. Four proteins were selected for further study with filled red circles (https://string-db.org/)

\section{Results}

\section{Identification of differently expressed proteins}

The clinical information of the five patients was summarized in Table 1. The five pairs of cancer tissues and adjacent normal tissues were analyzed by label-free mass spectrometry. Total 2297 proteins were identified and 308 proteins with significant differences were selected. Among these proteins, 102 proteins were expressed only in ESCC tissues (Table 2), 155 proteins were significantly up-regulated (Table 3 ) and 40 proteins were down-regulated in ESCC tissues (Table 4) $(P<0.05)$. Using the PANTHER classification system, we analyzed the biological significance of these proteins including the cellular component, molecular function and biological process (Fig. 1). The majority of proteins belonged to cell part proteins (37.3\%) and organelle proteins $(30.1 \%)$, possessed the ability of binding (41.8\%) and catalytic activity (25.8\%), and involved in the cellular process (29.6\%), metabolic process $(20.2 \%)$, cellular component organization or biogenesis (16.3\%). 


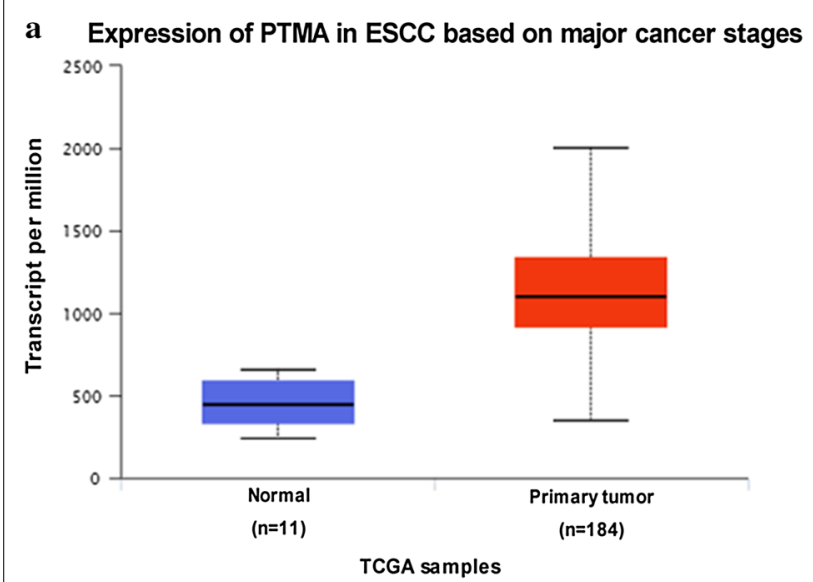

c Expression of PPP1CA in ESCC based on major cancer stages

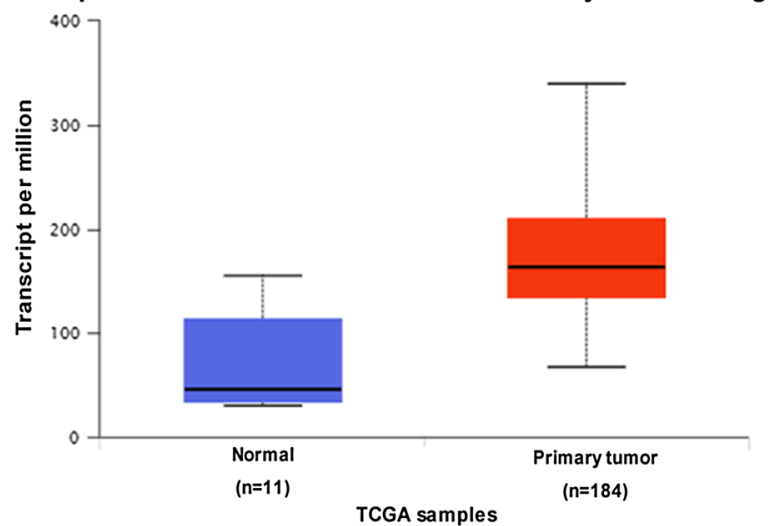

b Expression of PAK2 in ESCC based on major cancer stages

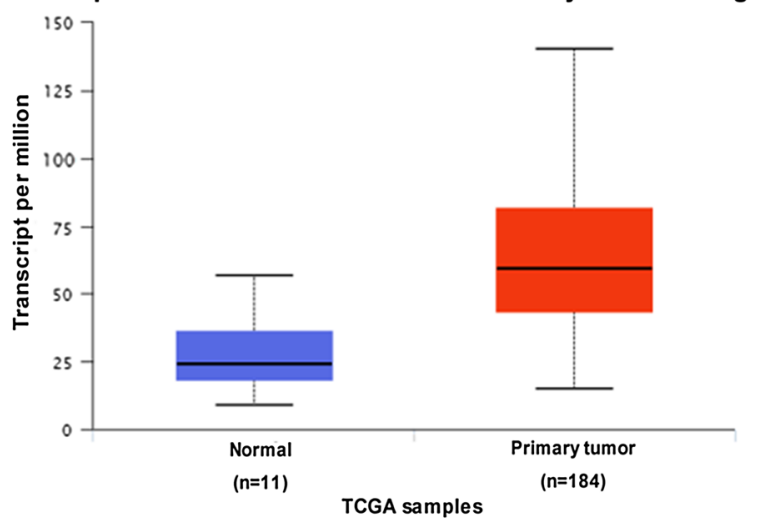

d Expression of HMGB2 in ESCC based on major cancer stages

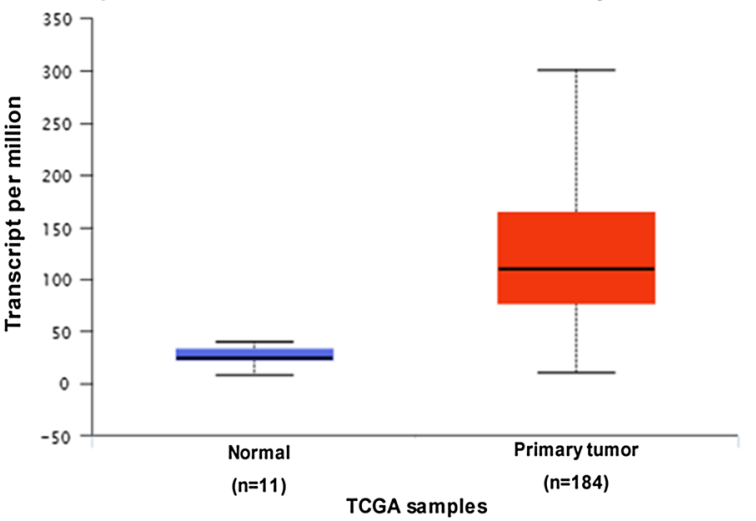

Fig. 4 The expression of PTMA, PAK2, PPP1CA and HMGB2 in ESCC based on major cancer stages. In the TCGA databases, the four genes were up-regulated in EC patients $(P<0.001)$. (http://ualcan.path.uab.edu/analysis.html)

Bioinformatics analysis of differentially expressed proteins A volcano plot was generated based on the differential expression ratio and $P$ value (Fig. $2 \mathrm{a}$ ). Moreover, the heat map of significantly different proteins was shown in Fig. 2b by using Morpheus (https://software.broadinsti tute.org/morpheus). Further protein-protein interaction analysis of the differently expressed proteins was performed by STRING, the result was shown in Fig. 3. Out of the four proteins selected for next analysis, the PPI network analysis revealed that PTMA was a valid target of c-myc transcriptional activation, while PPP1CA was involved in down-regulation of TGF-beta receptor signaling. PAK2 plays a role in apoptosis and activation of Rac, while HMGB2 is participating in chromatin regulation and retinoblastoma in cancer. Above mentioned, all these four proteins were associated with the occurrence and development of cancer. Bioinformatics analysis of the four genes from TCGA database revealed that the four genes up-regulated in gene level in EC tissue (Fig. 4). Whether these four genes can be used as biomarkers of esophageal cancer remains to be further studied.

\section{Validation of differentially expressed proteins by Western} Blot

To further validate the LC-MS/MS results, we evaluated the four up-regulated proteins (PTMA, PAK2, PPP1CA, HMGB2) and the five down-regulated proteins [Caveolin, Integrin beta-1, Collagen alpha-2(VI), Leiomodin-1 and Vinculin] with Western Blot on the same samples. Compared with adjacent normal tissues, the protein expression of PTMA, PAK2, PPP1CA, HMGB2 were upregulated (Fig. 5a, b), and the protein expression of Caveolin, Integrin beta-1, Collagen alpha-2(VI), Leiomodin-1, Vinculin were down-regulated in ESCC tissues from four pairs of samples (Fig. 5c, d). The results showed that the trends expression of these proteins were consistent with the LC-MS results.

\section{Validation of PTMA involved in ESCC by QDB and IHC}

In order to validate the proteins identified by mass spectrometric, the QDB technique was applied in a larger set of samples. We collected the samples of 64 patients, and the relevant clinical information was summarized in 

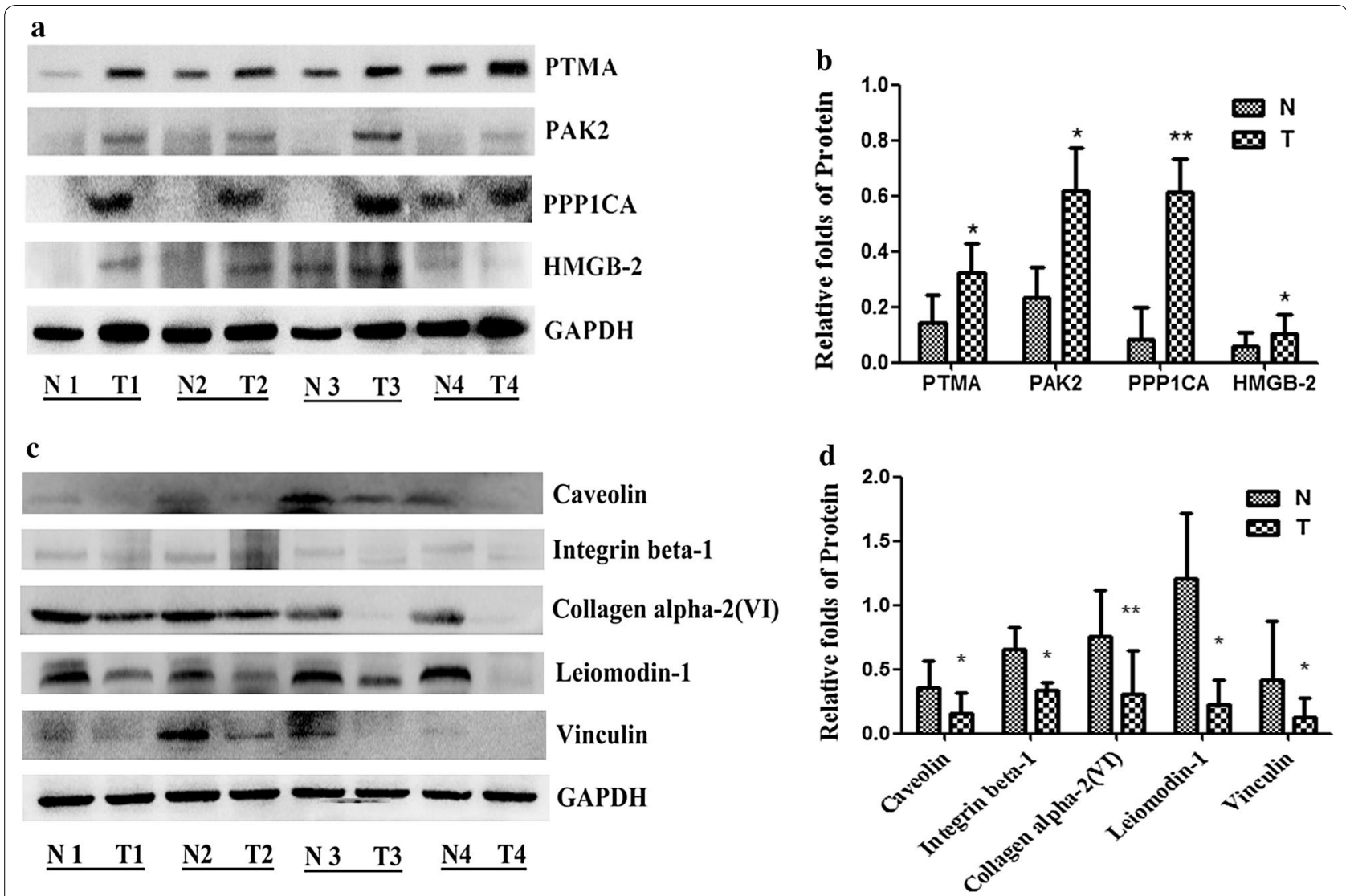

Fig. 5 The differentially expressed proteins were validated by Western Blot. Compared with adjacent normal tissues, the protein expression of PTMA, PAK2, PPP1CA, HMGB2 were up-regulated (a, b), and the protein expression of Caveolin, Integrin beta-1, Collagen alpha-2(VI), Leiomodin-1, Vinculin were down-regulated in ESCC tissues from four pairs of samples $(\mathbf{c}, \mathbf{d})$. Representative immunoblot images $(\mathbf{a}, \mathbf{c})$ and histograms (mean $\pm \mathrm{SD} ; \mathbf{b}, \mathbf{d})$.The experiments were repeated at least three times, $\mathrm{N}$ represented normal tissues and $\mathrm{T}$ represented tumor tissues

Table 5. In the analysis of 64 patient samples, we found that 53 out of 64 esophageal cancer tissues showed higher PTMA expression than in the normal tissues $(P<0.001)$ (Fig. 6). This trend was in accordance with the previous data. To further validate the QDB results, we performed the tissue microarray analysis by IHC. The results showed that among 117 pairs of tissues, the high expression rate of PTMA in tumor tissues was 98\% (115/117). A significant overexpression of PTMA was found in tumor tissues in contrast to adjacent normal tissues $(P<0.01)$ (Fig. 7$)$. The sample information in the chip is summarized in Tables 6 and 7. We further evaluated the expression pattern of PTMA with the progression, and analyzed the PTMA expression trend in the different tumor Grades. The results revealed that the PTMA expression was up-regulated gradually along the progression of ESCC (Fig. 8). The PTMA expression ratio between tumor and adjacent normal tissue was significantly increased along with the progression $(P<0.05)$. So we can suspect that PTMA might be participating in the development of esophageal cancer.

\section{Discussions}

At present, most patients with esophageal cancer are diagnosed at the late and advanced stages [17]. It is thus urgent to reveal biomarkers related to the progression of esophageal cancer for early diagnosis. Recently, several biomarkers were identified in EC detection, diagnosis, treatment and prognosis. For example, the epidermal growth factor receptor (EGFR), vascular endothelial growth factor (VEGF) and estrogen receptor (ER) were important detection factors for immunohistochemistry in EC [18-20]. In blood, the serum p53 antibody had a potential diagnostic value for EC, however, the detection was limited by its low sensitivity [21]. Therefore, we need to discover and verify more biomarker candidates for the prediction, diagnosis, treatment and prognosis of esophageal cancer.

Mass spectrometry is an effective method for finding distinct molecular regulators, between normal tissues and cancer tissues [22]. In current study, we proposed a significant proteomics profiling difference including 308 proteins. However, compare to previous tissue-based 
Table 5 The clinical features of ESCC patients for QDB analysis

\begin{tabular}{|c|c|c|c|c|c|}
\hline No. & Gender & Age & Organ/anatomic site & Grade & TNM \\
\hline 1 & Male & 69 & esophagus & $\|$ & T1NOMO \\
\hline 2 & Male & 61 & esophagus & । & TONOMO \\
\hline 3 & Male & 59 & esophagus & $\|$ & T3NOMO \\
\hline 4 & Female & 65 & esophagus & । & TONOMO \\
\hline 5 & Male & 52 & esophagus & $\|-\| \|$ & T3NOMO \\
\hline 6 & Female & 73 & esophagus & $|-| \mid$ & T1NOMO \\
\hline 7 & Male & 46 & esophagus & । & TONOMO \\
\hline 8 & Male & 64 & Lower segment of esophagus & $\|$ & T3N2MO \\
\hline 9 & Male & 57 & Mid-thoracic esophagus & $\|$ & T3NOMO \\
\hline 10 & Male & 54 & Mid-thoracic esophagus & $\|-\| \|$ & T3NOMO \\
\hline 11 & Male & 72 & Mid-thoracic esophagus & $\|$ & T3N3M0 \\
\hline 12 & Male & 66 & Mid-thoracic esophagus & $\|$ & T3N3M0 \\
\hline 13 & Male & 62 & Middle-lower esophagus & $\|$ & T1NOMO \\
\hline 14 & Male & 60 & esophagus & $\|$ & T3NOMO \\
\hline 15 & Female & 60 & esophagus & $\|$ & T3NOMO \\
\hline 16 & Male & 64 & esophagus & $\|$ & T3NOMO \\
\hline 17 & Female & 58 & Lower thoracic esophagus & III & T3NOMO \\
\hline 18 & Male & 53 & esophagus & $\|$ & T3NOMO \\
\hline 19 & Male & 65 & Lower thoracic esophagus & $\|-\| I \|$ & T3NOMO \\
\hline 20 & Female & 60 & Mid-thoracic esophagus & $|-|||$ & T3NOMO \\
\hline 21 & Male & 69 & Middle-lower esophagus & $\|$ & T3N3M0 \\
\hline 22 & Female & 66 & esophagus & $\|-I I I$ & T3N2MO \\
\hline 23 & Female & 67 & Lower segment of esophagus & $\|-I I I$ & T3N3M1 \\
\hline 24 & Male & 67 & Mid-thoracic esophagus & III & T3N1M0 \\
\hline 25 & Female & 55 & Mid-thoracic esophagus & $\|$ & T2N1M0 \\
\hline 26 & Female & 61 & Mid-thoracic esophagus & $|-| \mid$ & T1N2M0 \\
\hline 27 & Male & 68 & esophagus & $\|-I I I$ & T3N2MO \\
\hline 28 & Female & 48 & Mid-thoracic esophagus & $|-| \mid$ & T3NOMO \\
\hline 29 & Female & 63 & Mid-thoracic esophagus & $\|$ & T1N1M0 \\
\hline 30 & Male & 70 & Lower segment of esophagus & $\|$ & T2N1MO \\
\hline 31 & Female & 59 & Mid-thoracic esophagus & III & T3N1M0 \\
\hline 32 & Female & 48 & Mid-thoracic esophagus & $\|$ & T3NOMO \\
\hline 33 & Female & 53 & Mid-thoracic esophagus & $\|$ & T3N2M1 \\
\hline 34 & Female & 58 & Lower thoracic esophagus & $|-| \mid$ & T3NOMO \\
\hline 35 & Male & 62 & Mid-thoracic esophagus & $\|$ & T2NOMO \\
\hline 36 & Female & 59 & esophagus & $\|$ & T3N1M1 \\
\hline 37 & Female & 57 & esophagus & $\|$ & T3NOMO \\
\hline 38 & Female & 57 & Lower thoracic esophagus & $\|$ & T3N1M1 \\
\hline 39 & Female & 62 & Mid-thoracic esophagus & $|-| \mid$ & T3NOMO \\
\hline 40 & Female & 69 & Mid-thoracic esophagus & $\|-\| \|$ & T3N1M1 \\
\hline 41 & Female & 61 & Mid-thoracic esophagus & $\|$ & T3N2M1 \\
\hline 42 & Female & 67 & Mid-thoracic esophagus & $\|$ & T2NOMO \\
\hline 43 & Female & 47 & Mid-thoracic esophagus & $\|$ & T2NOMO \\
\hline 44 & Female & 69 & Lower thoracic esophagus & III & T2N2M1 \\
\hline 45 & Male & 66 & esophagus & $\|$ & T3NOMO \\
\hline 46 & Male & 72 & Mid-thoracic esophagus & $\|$ & T3NOMO \\
\hline 47 & Female & 69 & Mid-thoracic esophagus & $\|-\| \|$ & T3NOMO \\
\hline 48 & Female & 73 & Mid-thoracic esophagus & I & T1NOMO \\
\hline 49 & Male & 62 & esophagus & $\|$ & T3NOMO \\
\hline
\end{tabular}

Table 5 (continued)

\begin{tabular}{|c|c|c|c|c|c|}
\hline No. & Gender & Age & Organ/anatomic site & Grade & TNM \\
\hline 50 & Male & 58 & esophagus & $\|$ & T2NOMO \\
\hline 51 & Male & 56 & Lower segment of esophagus & $\|$ & T1NOMO \\
\hline 52 & Male & 56 & Middle-lower esophagus & $\|$ & T3NOMO \\
\hline 53 & Male & 56 & Middle-lower esophagus & $\|$ & T3NOMO \\
\hline 54 & Male & 55 & esophagus & $|-| \mid$ & T3NOMO \\
\hline 55 & Female & 61 & esophagus & $\mid-\|$ & T3NOMO \\
\hline 56 & Female & 71 & Middle-lower esophagus & $\mid-\|$ & T1N0M0 \\
\hline 57 & Male & 61 & esophagus & $\|-\| \|$ & T3N3M1 \\
\hline 58 & Male & 62 & Upper thoracic esophagus & III & T3NOMO \\
\hline 59 & Male & 67 & Mid-thoracic esophagus & 1 & T1N0M0 \\
\hline 60 & Male & 65 & esophagus & 1 & T3NOMO \\
\hline 61 & Male & 58 & esophagus & $\|-\| \|$ & T2N1M1 \\
\hline 62 & Male & 49 & Lower segment of esophagus & 1 & T1N0M0 \\
\hline 63 & Female & 66 & esophagus & III & T3N1M1 \\
\hline 64 & Male & 70 & esophagus & 1 & T1N0M0 \\
\hline
\end{tabular}

ESCC proteomics study, a poor overlap of proteome profiling was noticed. There are several potential reasons. First, like many other cancers, ESCC is a heterogeneous cancer with different gene expression profiles from different populations [23]. Recently, the whole-genome sequencing revealed the diverse models of structural variations in ESCC, which indicted the biological differences among patients [24]. Therefore, the proteome variation may be a consequence of distinct molecular signatures that exist in ESCC. Another reasons could be related to the different experiment design, some of studies pooled several individual samples into a sample pooling, which would also lead to potential difference compare to our individual analysis [25]. The difference of data analysis method would be another reason too, most of the labeled-based MS approach selected the expression fold change as the major criteria. In our study, with a label-free approach, we proposed paired Student's $t$-test significance as the main criteria. Such difference could lead to a different proteome profiling. The poor overlap indicated the importance of large-scale validation of biomarker. Thus we suggest in future studies, the proposed novel biomarker should be validated in a larger population no less than 100 samples. Besides TMA, our group recently developed QDB as a novel fast and accurate validation approach, which can easily validate biomarkers up to thousand samples [16].

Human prothymosin- $\alpha$ (PTMA) is a 109 amino acid protein belonged to the $\alpha$-thymosin family, which is ubiquitously distributed in mammalian blood, tissues and especially abundant in lymphoid cells. However, its role still remains elusive. The growing evidences suggested that PTMA being an important immune mediator as well 

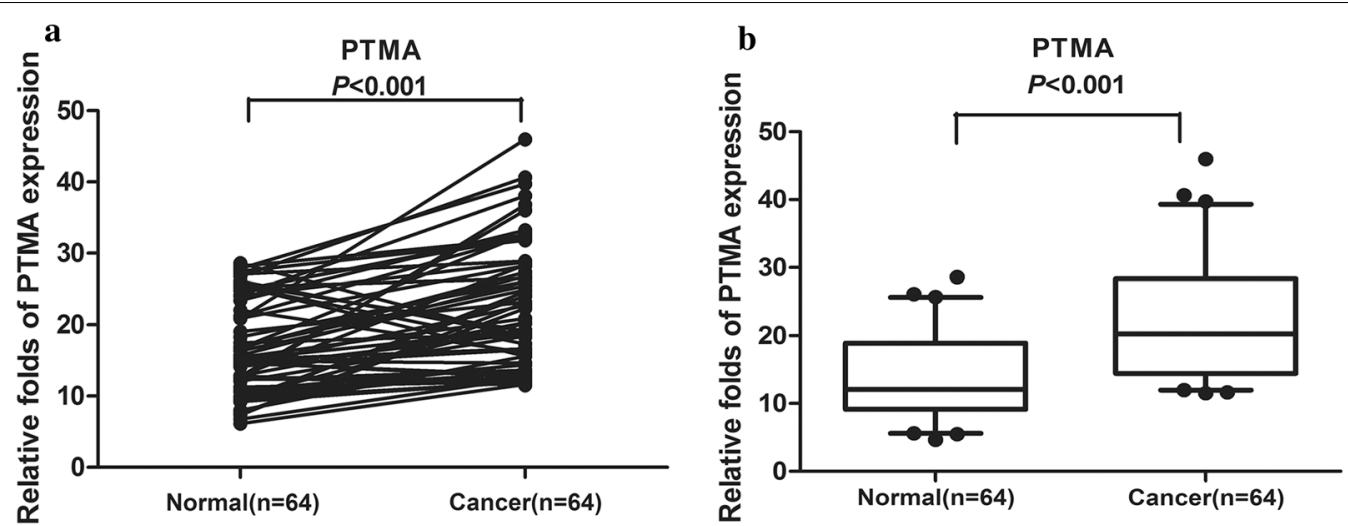

Fig. 6 The relative PTMA expression was tested by QDB in ESCC and adjacent normal tissues from 64 esophageal cancer patients. a The differential expression of PTMA was shown in each pair of tissues. $\mathbf{b}$ The PTMA expression was up-regulated in esophageal cancer tissues from the average of 64 pairs of tissues

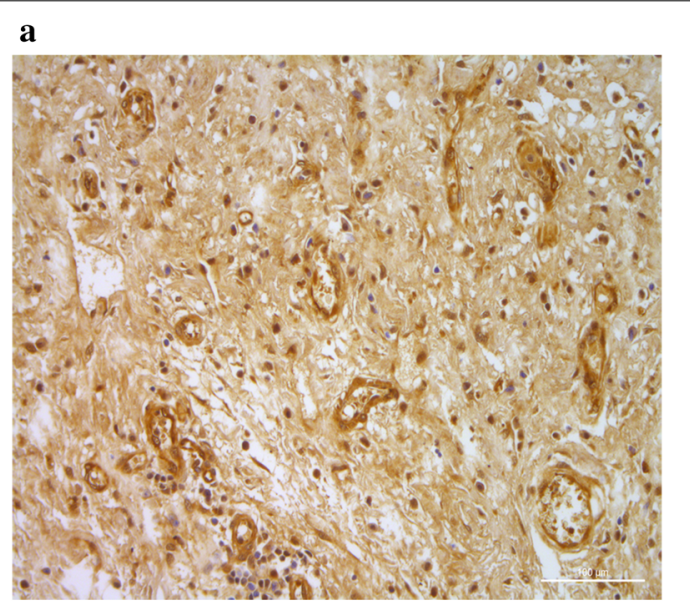

$$
\text { c }
$$

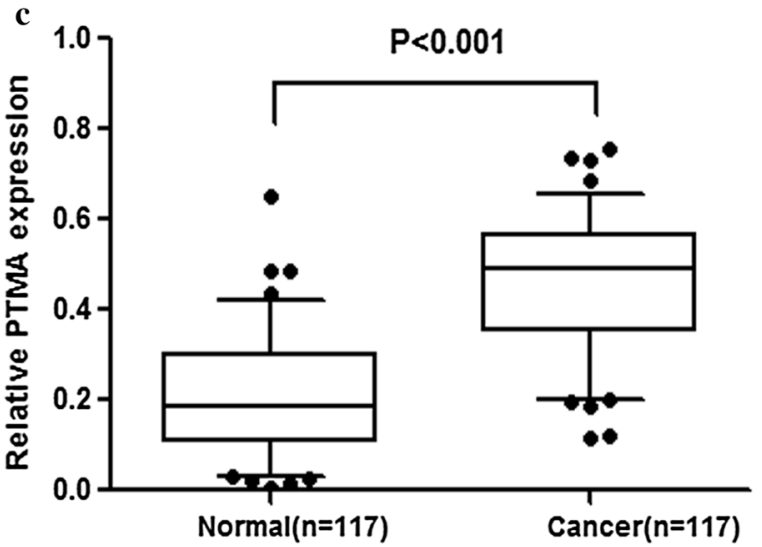

Fig. 7 The relative PTMA expression was tested by IHC in ESCC and adjacent normal tissues among 117 pairs of tissues ( $\times 200)$. a The expression of PTMA in adjacent normal tissues were presented. $\mathbf{b}$ The expression of PTMA in esophageal cancer were up-regulated. $\mathbf{c}$ The gray-scale analysis of immunohistochemical results $(P<0.001)$

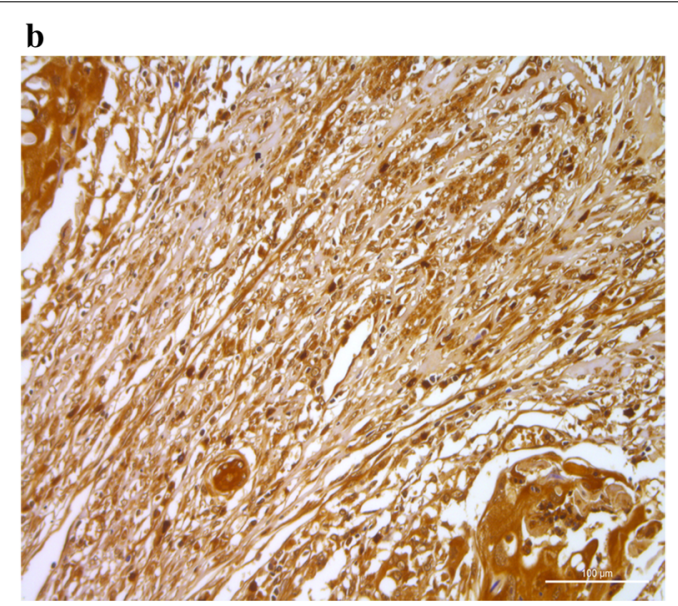

$P<0.001$ 
Table 6 The 35 pairs samples in tissue microarrays (TMA) (ES701) for immunohistochemistry analysis

\begin{tabular}{|c|c|c|c|c|c|}
\hline No. & Gender & Age & Organ/anatomic site & Grade & TNM \\
\hline 1 & Male & 60 & Esophagus & $\|$ & T3N1M0 \\
\hline 2 & Male & 60 & Esophagus & - & - \\
\hline 3 & Male & 44 & Esophagus & 1 & T3N1M0 \\
\hline 4 & Male & 44 & Esophagus & - & - \\
\hline 5 & Male & 50 & Esophagus & 1 & $\mathrm{~T} 3 \mathrm{~N} 2 \mathrm{MO}$ \\
\hline 6 & Male & 50 & Esophagus & - & - \\
\hline 7 & Male & 53 & Esophagus & 1 & T3NOMO \\
\hline 8 & Male & 53 & Esophagus & - & - \\
\hline 9 & Male & 64 & Esophagus & 1 & T3N1M0 \\
\hline 10 & Male & 64 & Esophagus & - & - \\
\hline 11 & Male & 69 & Esophagus & I & T3NOMO \\
\hline 12 & Male & 69 & Esophagus & - & - \\
\hline 13 & Male & 59 & Esophagus & 1 & T3N0MO \\
\hline 14 & Male & 59 & Esophagus & - & - \\
\hline 15 & Male & 60 & Esophagus & I & T3N1M0 \\
\hline 16 & Male & 60 & Esophagus & - & - \\
\hline 17 & Male & 72 & Esophagus & 1 & T3N1M0 \\
\hline 18 & Male & 72 & Esophagus & - & - \\
\hline 19 & Female & 60 & Esophagus & I & T3N1M0 \\
\hline 20 & Female & 60 & Esophagus & - & - \\
\hline 21 & Female & 75 & Esophagus & III & T3NOMO \\
\hline 22 & Female & 75 & Esophagus & - & - \\
\hline 23 & Male & 57 & Esophagus & $\|$ & T3N1M0 \\
\hline 24 & Male & 57 & Esophagus & - & - \\
\hline 25 & Female & 54 & Esophagus & $\|$ & T3N1M0 \\
\hline 26 & Female & 54 & Esophagus & - & - \\
\hline 27 & Male & 45 & Esophagus & III & T3NOMO \\
\hline 28 & Male & 45 & Esophagus & - & - \\
\hline 29 & Male & 52 & Esophagus & $\|$ & T3NOMO \\
\hline 30 & Male & 52 & Esophagus & - & - \\
\hline 31 & Male & 68 & Esophagus & - & T3NOMO \\
\hline 32 & Male & 68 & Esophagus & - & - \\
\hline 33 & Male & 67 & Esophagus & I & T3NOMO \\
\hline 34 & Male & 67 & Esophagus & - & - \\
\hline 35 & Male & 55 & Esophagus & I & T3NOMO \\
\hline 36 & Male & 55 & Esophagus & - & - \\
\hline 37 & Male & 71 & Esophagus & I & T3N1M0 \\
\hline 38 & Male & 71 & Esophagus & - & - \\
\hline 39 & Male & 63 & Esophagus & III & T3N1M0 \\
\hline 40 & Male & 63 & Esophagus & - & - \\
\hline 41 & Male & 67 & Esophagus & III & T3N1M0 \\
\hline 42 & Male & 67 & Esophagus & - & - \\
\hline 43 & Male & 57 & Esophagus & III & T3NOMO \\
\hline 44 & Male & 57 & Esophagus & - & - \\
\hline 45 & Male & 63 & Esophagus & III & T3NOMO \\
\hline 46 & Male & 63 & Esophagus & - & - \\
\hline 47 & Male & 57 & Esophagus & III & T3N1M0 \\
\hline 48 & Male & 57 & Esophagus & - & - \\
\hline 49 & Male & 58 & Esophagus & III & T3N1M0 \\
\hline
\end{tabular}

Table 6 (continued)

\begin{tabular}{|c|c|c|c|c|c|}
\hline No. & Gender & Age & Organ/anatomic site & Grade & TNM \\
\hline 50 & Male & 58 & Esophagus & - & - \\
\hline 51 & Male & 53 & Esophagus & $\|$ & T3N1M0 \\
\hline 52 & Male & 53 & Esophagus & - & - \\
\hline 53 & Male & 49 & Esophagus & 1 & T3N1M0 \\
\hline 54 & Male & 49 & Esophagus & - & - \\
\hline 55 & Male & 68 & Esophagus & III & T3N1M0 \\
\hline 56 & Male & 68 & Esophagus & - & - \\
\hline 57 & Male & 48 & Esophagus & III & T3NOMO \\
\hline 58 & Male & 48 & Esophagus & - & - \\
\hline 59 & Female & 58 & Esophagus & $\|$ & T3N1M0 \\
\hline 60 & Female & 58 & Esophagus & - & - \\
\hline 61 & Male & 44 & Esophagus & III & T3N1M0 \\
\hline 62 & Male & 44 & Esophagus & - & - \\
\hline 63 & Male & 63 & Esophagus & $\|$ & T3N1M0 \\
\hline 64 & Male & 63 & Esophagus & - & - \\
\hline 65 & Male & 68 & Esophagus & III & T3N1M0 \\
\hline 66 & Male & 68 & Esophagus & - & - \\
\hline 67 & Female & 68 & Esophagus & III & T3N1M0 \\
\hline 68 & Female & 68 & Esophagus & - & - \\
\hline 69 & Male & 62 & Esophagus & III & T2M1N1B \\
\hline 70 & Male & 62 & Esophagus & - & - \\
\hline
\end{tabular}

as a biomarker might eventually become a new therapeutic target or diagnostic method in several diseases such as cancer and inflammation [26]. So we focused on the possibility of PTMA as a biomarker of ESCC.

The proteomic studies show that PTMA exerts multifunction in nuclear and cytoplasmic. In proliferating cells, PTMA mainly locates in nuclear depending on the C-terminus signal sequence, but this protein can be transferred from the nucleus into the cytoplasmic during the cell extraction process $[27,28]$. PTMA may mediate the chromatin activity by participated the nuclear-protein complex. In cytoplasmic, the function of PTMA is related to the state of phosphorylation, for example, the Thr7 is the only residue phosphorylated in carcinogenic lymphocytes while the Thr12 or Thr13 phosphorylated in normal lymphocytes $[29,30]$. The co-immunoprecipitation experiments shows that PTMA interact with SET, ANP32A and ANP32B to form the complex, which is related to the cell proliferation, membrane trafficking, proteolytic processing and so on [31-33].

PTMA is known to play an important role in cell growth, proliferation, apoptosis and so on [34,35]. Recent studies have confirmed that overexpression of PTMA is involved in the development of various malignancies, including colorectal, bladder, lung, and liver cancer [3638]. In vivo tumorigenesis, the PTMA expression promotes the transplant tumor growth in mice and speeds 
Table 7 The 96 pairs samples in tissue microarrays (TMA) (ES1922) for immunohistochemistry analysis

\begin{tabular}{|c|c|c|c|c|c|c|c|c|c|c|c|}
\hline & & & & & & & & & & & \\
\hline No. & Gender & Age & Organ/anatomic site & Grade & TNM & 50 & Female & 58 & Esophagus & - & - \\
\hline 1 & Male & 58 & Esophagus & । & T3NOMO & 51 & Male & 63 & Esophagus & । & T3NOMO \\
\hline 2 & Male & 58 & Esophagus & - & - & 52 & Male & 63 & Esophagus & - & - \\
\hline 3 & Male & 68 & Esophagus & । & T3N1M0 & 53 & Female & 68 & Esophagus & । & T2NOMO \\
\hline 4 & Male & 68 & Esophagus & - & - & 54 & Female & 68 & Esophagus & - & - \\
\hline 5 & Male & 52 & Esophagus & 1 & T1NOMO & 55 & Female & 68 & Esophagus & । & T3NOMO \\
\hline 6 & Male & 52 & Esophagus & - & - & 56 & Female & 68 & Esophagus & - & - \\
\hline 7 & Female & 66 & Esophagus & । & T3NOMO & 57 & Male & 58 & Esophagus & । & T3NOMO \\
\hline 8 & Female & 66 & Esophagus & - & - & 58 & Male & 58 & Esophagus & - & - \\
\hline 9 & Male & 72 & Esophagus & I & T3N1M0 & 59 & Female & 60 & Esophagus & I & T3NOMO \\
\hline 10 & Male & 72 & Esophagus & - & - & 60 & Female & 60 & Esophagus & - & - \\
\hline 11 & Male & 67 & Esophagus & I & T3NOMO & 61 & Male & 70 & Esophagus & $\|$ & T2N1M0 \\
\hline 12 & Male & 67 & Esophagus & - & - & 62 & Male & 70 & Esophagus & - & - \\
\hline 13 & Male & 66 & Esophagus & I & T3N1M0 & 63 & Female & 61 & Esophagus & I & T3NOMO \\
\hline 14 & Male & 66 & Esophagus & - & - & 64 & Female & 61 & Esophagus & - & - \\
\hline 15 & Male & 55 & Esophagus & I & T3N1M0 & 65 & Male & 54 & Esophagus & $\|$ & T3NOMO \\
\hline 16 & Male & 55 & Esophagus & - & - & 66 & Male & 54 & Esophagus & - & - \\
\hline 17 & Male & 67 & Esophagus & I & T3N1M0 & 67 & Male & 45 & Esophagus & $\|$ & T3NOMO \\
\hline 18 & Male & 67 & Esophagus & - & - & 68 & Male & 45 & Esophagus & - & - \\
\hline 19 & Female & 71 & Esophagus & I & T3NOMO & 69 & Male & 75 & Esophagus & III & T3NOMO \\
\hline 20 & Female & 71 & Esophagus & - & - & 70 & Male & 75 & Esophagus & - & - \\
\hline 21 & Male & 69 & Esophagus & I & T3NOMO & 71 & Male & 63 & Esophagus & I & T3NOMO \\
\hline 22 & Male & 69 & Esophagus & - & - & 72 & Male & 63 & Esophagus & - & - \\
\hline 23 & Male & 68 & Esophagus & I & T3NOMO & 73 & Male & 68 & Esophagus & I & T3NOMO \\
\hline 24 & Male & 68 & Esophagus & - & - & 74 & Male & 68 & Esophagus & - & - \\
\hline 25 & Male & 44 & Esophagus & I & T3N1M0 & 75 & Female & 50 & Esophagus & $\|$ & T3NOMO \\
\hline 26 & Male & 44 & Esophagus & - & - & 76 & Female & 50 & Esophagus & - & - \\
\hline 27 & Female & 63 & Esophagus & I & T2NOMO & 77 & Male & 72 & Esophagus & III & T3NOMO \\
\hline 28 & Female & 63 & Esophagus & - & - & 78 & Male & 72 & Esophagus & - & - \\
\hline 29 & Female & 54 & Esophagus & I & T3N1M0 & 79 & Female & 53 & Esophagus & III & T3NOMO \\
\hline 30 & Female & 54 & Esophagus & - & - & 80 & Female & 53 & Esophagus & - & - \\
\hline 31 & Male & 60 & Esophagus & I & T2NOMO & 81 & Male & 69 & Esophagus & $\|$ & T3N1M0 \\
\hline 32 & Male & 60 & Esophagus & - & - & 82 & Male & 69 & Esophagus & - & - \\
\hline 33 & Female & 68 & Esophagus & $\|$ & T3NOMO & 83 & Male & 57 & Esophagus & I & T3NOMO \\
\hline 34 & Female & 68 & Esophagus & - & - & 84 & Male & 57 & Esophagus & - & - \\
\hline 35 & Male & 49 & Esophagus & I & T3N1M0 & 85 & Male & 68 & Esophagus & III & T3N1M0 \\
\hline 36 & Male & 49 & Esophagus & - & - & 86 & Male & 68 & Esophagus & - & - \\
\hline 37 & Male & 61 & Esophagus & I & T3NOMO & 87 & Male & 51 & Esophagus & III & T3NOMO \\
\hline 38 & Male & 61 & Esophagus & - & - & 88 & Male & 51 & Esophagus & - & - \\
\hline 39 & Female & 69 & Esophagus & । & T3N1M0 & 89 & Male & 70 & Esophagus & I & T3N1M0 \\
\hline 40 & Female & 69 & Esophagus & - & - & 90 & Male & 70 & Esophagus & - & - \\
\hline 41 & Male & 49 & Esophagus & I & T3N1M0 & 91 & Male & 68 & Esophagus & $\|$ & T3N1M0 \\
\hline 42 & Male & 49 & Esophagus & - & - & 92 & Male & 68 & Esophagus & - & - \\
\hline 43 & Male & 68 & Esophagus & I & T3NOMO & 93 & Male & 57 & Esophagus & III & T3NOMO \\
\hline 44 & Male & 68 & Esophagus & - & - & 94 & Male & 57 & Esophagus & - & - \\
\hline 45 & Male & 66 & Esophagus & $\|$ & T3NOMO & 95 & Male & 48 & Esophagus & $\|$ & T3NOMO \\
\hline 46 & Male & 66 & Esophagus & - & - & 96 & Male & 48 & Esophagus & - & - \\
\hline 47 & Male & 53 & Esophagus & $\|$ & T3N1M0 & 97 & Male & 63 & Esophagus & III & T3N1M0 \\
\hline 48 & Male & 53 & Esophagus & - & - & 98 & Male & 63 & Esophagus & - & - \\
\hline
\end{tabular}

Table 7 (continued)

No. Gender Ag


Table 7 (continued)

\begin{tabular}{|c|c|c|c|c|c|c|c|c|c|c|c|}
\hline No. & Gender & Age & Organ/anatomic site & Grade & TNM & No. & Gender & Age & Organ/anatomic site & Grade & TNM \\
\hline 99 & Male & 65 & Esophagus & $\|$ & T3N0MO & 148 & Male & 74 & Esophagus & - & - \\
\hline 100 & Male & 65 & Esophagus & - & - & 149 & Male & 54 & Esophagus & 1 & T2NOMO \\
\hline 101 & Male & 71 & Esophagus & III & T3N1M0 & 150 & Male & 54 & Esophagus & - & - \\
\hline 102 & Male & 71 & Esophagus & - & - & 151 & Male & 64 & Esophagus & III & $\mathrm{T} 3 \mathrm{~N} 1 \mathrm{MO}$ \\
\hline 103 & Male & 78 & Esophagus & III & T3NOMO & 152 & Male & 64 & Esophagus & - & - \\
\hline 104 & Male & 78 & Esophagus & - & - & 153 & Male & 57 & Esophagus & I & T3N1M0 \\
\hline 105 & Male & 53 & Esophagus & $\|$ & T3N1M0 & 154 & Male & 57 & Esophagus & - & - \\
\hline 106 & Male & 53 & Esophagus & - & - & 155 & Male & 48 & Esophagus & III & T3NOMO \\
\hline 107 & Male & 57 & Esophagus & $\|$ & T3NOMO & 156 & Male & 48 & Esophagus & - & - \\
\hline 108 & Male & 57 & Esophagus & - & - & 157 & Female & 61 & Esophagus & III & T3NOMO \\
\hline 109 & Male & 63 & Esophagus & $\|$ & T3N1M0 & 158 & Female & 61 & Esophagus & - & - \\
\hline 110 & Male & 63 & Esophagus & - & - & 159 & Male & 61 & Esophagus & III & T3N1M0 \\
\hline 111 & Male & 63 & Esophagus & III & T3N1M0 & 160 & Male & 61 & Esophagus & - & - \\
\hline 112 & Male & 63 & Esophagus & - & - & 161 & Male & 65 & Esophagus & III & T3NOMO \\
\hline 113 & Female & 58 & Esophagus & I & T3N1M0 & 162 & Male & 65 & Esophagus & - & - \\
\hline 114 & Female & 58 & Esophagus & - & - & 163 & Male & 55 & Esophagus & III & T2NOMO \\
\hline 115 & Male & 50 & Esophagus & $\|$ & T2NOMO & 164 & Male & 55 & Esophagus & - & - \\
\hline 116 & Male & 50 & Esophagus & - & - & 165 & Female & 56 & Esophagus & III & T3NOMO \\
\hline 117 & Male & 44 & Esophagus & I & T3N1M0 & 166 & Female & 56 & Esophagus & - & - \\
\hline 118 & Male & 44 & Esophagus & - & - & 167 & Female & 73 & Esophagus & $\|$ & T3NOMO \\
\hline 119 & Male & 61 & Esophagus & 1 & T3N1M0 & 168 & Female & 73 & Esophagus & - & - \\
\hline 120 & Male & 61 & Esophagus & - & - & 169 & Male & 70 & Esophagus & III & T3NOMO \\
\hline 121 & Male & 61 & Esophagus & 1 & T3N1M0 & 170 & Male & 70 & Esophagus & - & - \\
\hline 122 & Male & 61 & Esophagus & - & - & 171 & Male & 53 & Esophagus & III & T3N1M0 \\
\hline 123 & Male & 57 & Esophagus & $\|$ & T3N1M0 & 172 & Male & 53 & Esophagus & - & - \\
\hline 124 & Male & 57 & Esophagus & - & - & 173 & Male & 67 & Esophagus & III & T2NOMO \\
\hline 125 & Male & 60 & Esophagus & 1 & T3N0MO & 174 & Male & 67 & Esophagus & - & - \\
\hline 126 & Male & 60 & Esophagus & - & - & 175 & Male & 69 & Esophagus & III & T3NOMO \\
\hline 127 & Male & 58 & Esophagus & $\|$ & T3N0MO & 176 & Male & 69 & Esophagus & - & - \\
\hline 128 & Male & 58 & Esophagus & - & - & 177 & Male & 68 & Esophagus & III & T3NOMO \\
\hline 129 & Male & 61 & Esophagus & $\|$ & T3N0MO & 178 & Male & 68 & Esophagus & - & - \\
\hline 130 & Male & 61 & Esophagus & - & - & 179 & Male & 64 & Esophagus & III & T3N0MO \\
\hline 131 & Male & 52 & Esophagus & 1 & T3N1M0 & 180 & Male & 64 & Esophagus & - & - \\
\hline 132 & Male & 52 & Esophagus & - & - & 181 & Male & 61 & Esophagus & III & T3N1M0 \\
\hline 133 & Female & 60 & Esophagus & $\|$ & T3N1M0 & 182 & Male & 61 & Esophagus & - & - \\
\hline 134 & Female & 60 & Esophagus & - & - & 183 & Male & 59 & Esophagus & III & T3N0MO \\
\hline 135 & Male & 68 & Esophagus & $\|$ & T3NOMO & 184 & Male & 59 & Esophagus & - & - \\
\hline 136 & Male & 68 & Esophagus & - & - & 185 & Male & 57 & Esophagus & III & T2NOMO \\
\hline 137 & Female & 43 & Esophagus & III & T3N1M0 & 186 & Male & 57 & Esophagus & - & - \\
\hline 138 & Female & 43 & Esophagus & - & - & 187 & Male & 64 & Esophagus & III & T3N0MO \\
\hline 139 & Male & 59 & Esophagus & III & T3N1M0 & 188 & Male & 64 & Esophagus & - & - \\
\hline 140 & Male & 59 & Esophagus & - & - & 189 & Female & 67 & Esophagus & I & T2NOMO \\
\hline 141 & Male & 55 & Esophagus & III & T3N1M0 & 190 & Female & 67 & Esophagus & - & - \\
\hline 142 & Male & 55 & Esophagus & - & - & 191 & Male & 47 & Esophagus & III & T2N0MO \\
\hline 143 & Male & 68 & Esophagus & III & T3N0M0 & 192 & Male & 47 & Esophagus & - & - \\
\hline 144 & Male & 68 & Esophagus & - & - & & & & & & \\
\hline 145 & Female & 70 & Esophagus & III & T3N0M0 & & & & & & \\
\hline 146 & Female & 70 & Esophagus & - & - & & & & & & \\
\hline 147 & Male & 74 & Esophagus & III & T2N0MO & & & & & & \\
\hline
\end{tabular}

Table 7 (continued) 

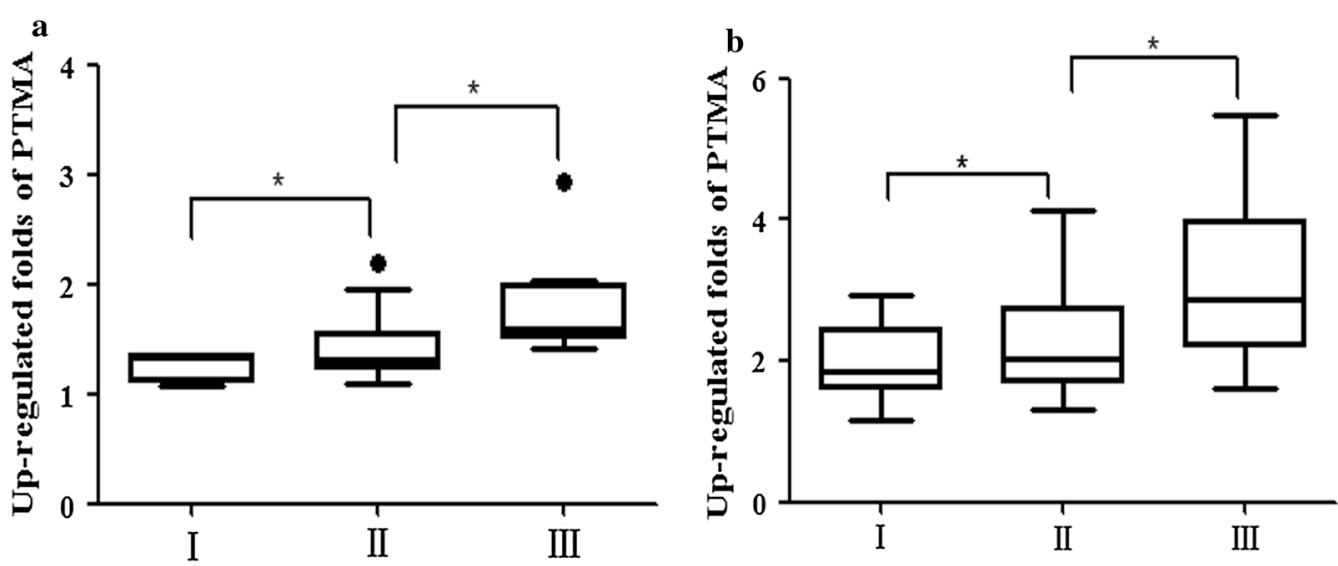

Fig. 8 The PTMA expression was up-regulated gradually along the progression of ESCC. a The PTMA expression trend at the different Grades in QDB samples. b The PTMA expression trend at the different Grades in IHC samples. I, II, III represented ESCC Grade I, Grade II and Grade III respectively. $(* P<0.05)$

up their death. Meanwhile, the PTMA interacts with TRIM21 directly to regulate the Nrf2 expression through p62/Keap1 signaling in human bladder cancer [39]. In the patients with squamous cell carcinoma (SCC), adenosquamous cell carcinoma (ASC) and adenocarcinoma (AC) of the gallbladder, the positive expression of PTMA may be associated with the tumorigenesis, tumor progression and prognosis in gallbladder tumor. In addition, the high expression of PTMA may be as an indicator in the prevention and early diagnosis of gallbladder tumor [40]. In addition to inducing cancer, Wang et al. discovered that PTMA as a new autoantigen regulated oral submucous fibroblast proliferation and extracellular matrix using human proteome microarray analysis. In addition, PTMA knockdown reversed TGF $\beta 1$-induced fibrosis process through reducing the protein levels of collagen I, $\alpha$-SMA and MMP [34]. However, there have been no evidences that PTMA participates in the pathogenesis of esophageal cancer.

Our mass spectrometry results showed that PTMA expression was up-regulated in ESCC tissues, and if the result was universal, it would provide a good biomarker for the diagnosis of ESCC. The traditional Western Blot is tedious, laborious and time-consuming for hundreds and thousands of large samples tests. In order to verify the results of mass spectrometry, we adopted the QDB technology invented recently, which was capable of highthroughput identification of target proteins from the perspective of biological experiments compared with Western Blot. QDB performed an affordable method for high-throughput immunoblot analysis and achieved relative or absolute quantification. In addition, the QDB needs less sample consumption, and the data can be conveniently read by a microplate reader. In HEK293 cells, the QDB successfully compared the levels of relative p65 levels between Luciferase and p65 clones in 71 pairs of samples. We have confirmed the accuracy and reliability of QDB from both cells and tissues [16]. As above mentioned, QDB is a convenient, reliable and affordable method. In our study, we confirmed that 53 out of 64 tested ESCC tissues had higher PTMA expression by the QDB, and the results were identified by classical IHC methods in 117 pairs of samples.

In this study, we included both explore experiment and validation experiment, using early and late stage samples. The results from explore experiment indicated that PTMA was overexpressed in all stages. We further evaluated the expression pattern of PTMA with the progression, and analyzed the PTMA expression trend in the different Grades. The results revealed that the PTMA expression was up-regulated gradually along the progression of ESCC, and the PTMA expression ratio between tumor and adjacent normal tissue was significantly increased along with the progression. As it is almost impossible to obtain the extreme early stage (such as the stage without any symptom, or the stage prior to Grade I), but from the trend between Grade I and III, we can suspect the expression ratio of PTMA would be a potential indicator for the progression, even in the early diagnosis.

\section{Conclusions}

In our research, we used label-free quantitative proteomics to detect differentially expressed protein profiles in ESCC tissues compared to control tissues. In total 2297 proteins were identified and 308 proteins with significant differences were selected for study. Based on in-depth bioinformatic analysis, the four up-regulated proteins 
[PTMA, PAK2, PPP1CA, HMGB2) and the five downregulated proteins Caveolin, Integrin beta-1, Collagen alpha-2(VI), Leiomodin-1 and Vinculin] were selected and validated in ESCC by Western Blot. Furthermore, we performed the QDB and IHC analysis in 64 patients and 117 patients, respectively. The PTMA expression was up-regulated gradually along the progression of ESCC, and the PTMA expression ratio between tumor and adjacent normal tissue was significantly increased along with the progression. Therefore, the PTMA is suggested as a candidate biomarker for ESCC. Our research also presents a new methodological strategy for the identification and validation of novel cancer biomarkers by combining quantitative proteomic with QDB.

\section{Authors' contributions}

JM and LW conceived the experiments; YPZ, XYQ, CCY, YZ and XXL performed the experiments; CCY, SJY, YXX and CHY collected the clinical materials; JM and CZ analyzed the protein data;WGJ, GT and JDZ conducted the statistical analysis; XRL and JB modified the paper. All authors read and approved the final manuscript.

\section{Author details \\ ${ }^{1}$ Precision Medicine Research Center, Binzhou Medical University, No. 346 Guanhai Rd., Laishan District, Yantai 264003, Shandong Province, People's Republic of China. ${ }^{2}$ Department of Anesthesiology, The Affiliated Yantai Yuhuangding Hospital of Qing Dao University, No. 20 Yudong Rd., Zhifu District, Yantai S264009, Shandong, People's Republic of China. ${ }^{3}$ Department of Ultrasound, Yantai Affiliated Hospital of Binzhou Medical University, No. 717 Jinfu Rd., Muping District, Binzhou 264100, Shandong Province, People's Republic of China. ${ }^{4}$ State Key Laboratory of Ophthalmology, Zhongshan Oph- thalmic Center, Sun Yat-Sen University, Guangzhou 510060, People's Republic of China. ${ }^{5}$ Department of Chemistry, BMC, Uppsala University, PO Box 599, Husargatan 3, 75124 Uppsala, Sweden. ${ }^{6}$ Yantai Zestern Biotechnique Co. LTD, 39 Keji Ave. Bioasis, Yantai, People's Republic of China. ${ }^{7}$ Department of Tho- racic Surgery, The First Affiliated Hospital of Harbin Medical University, No. 23, Youzheng Street, Nangang District, Harbin 150000, Heilongjiang Province, People's Republic of China.}

\section{Competing interests}

All authors declare that they have no competing interests. Jiandi Zhang declares competing interests, and he has filed patent applications. Jiandi Zhang is the founders of Yantai Zestern Biotechnique Co. LTD, a startup company with interest to commercialize the QDB technique and QDB plate.

\section{Availability of data and materials}

The data will be made available upon publication.

\section{Consent for publication}

Not applicable.

\section{Ethics approval and consent to participate}

The study was approved by the Human Research Ethics Committee of Binzhou Medical University (2016-37).

\section{Funding}

This work is supported by the National Natural Science Foundation of China $(81670855,31671139)$ for sample collection and publication charges, Key Research and Development Plan of Shandong Province (2016GSF201100, 2017GSF218113, 2018GSF118131, 2018GSF118183) for MS experiments and IHC TMA analysis, Yantai science and technology plan (2017WS102) and Doctoral fund of Shandong Natural Science Foundation (ZR2017BC063) for antibody consumption, BZMC Scientific Research Foundation (BY2017KYQD08) for QDB analysis, Scientific Research Foundation for Returned Overseas Chinese Scholars of the Education Office of Heilongjiang Province (LC2009C21) for interpretation of data, Development Plan of Traditional Chinese Medicine Science in Shandong Province (2017-237) for general lab facility.

\section{Publisher's Note}

Springer Nature remains neutral with regard to jurisdictional claims in published maps and institutional affiliations.

Received: 21 December 2018 Accepted: 25 March 2019

Published online: 05 April 2019

\section{References}

1. Pennathur A, et al. Oesophageal carcinoma. Lancet. 2013:381(9864):400-12.

2. Zhang Y. Epidemiology of esophageal cancer. World J Gastroenterol. 2013;19(34):5598-606.

3. Torre LA, et al. Global cancer statistics, 2012. CA Cancer J Clin. 2015;65(2):87-108.

4. Vizcaino AP, et al. Time trends incidence of both major histologic types of esophageal carcinomas in selected countries, 1973-1995. Int J Cancer. 2002;99(6):860-8

5. Tran GD, et al. Prospective study of risk factors for esophageal and gastric cancers in the Linxian general population trial cohort in China. Int J Cancer. 2005;113(3):456-63.

6. Lambert R, Hainaut P. The multidisciplinary management of gastrointestinal cancer. Epidemiology of oesophagogastric cancer. Best Pract Res Clin Gastroenterol. 2007;21(6):921-45.

7. McGuire S. World Cancer Report 2014. Geneva, Switzerland: World Health Organization, International Agency for Research on Cancer, WHO Press, 2015. Adv Nutr. 2016;7(2):418-9.

8. Sedighi $\mathrm{M}$, et al. Matrix metalloproteinase-13-a potential biomarker for detection and prognostic assessment of patients with esophageal squamous cell carcinoma. Asian Pac J Cancer Prev. 2016;17(6):2781-5.

9. Xie Z, et al. Salivary microRNAs as promising biomarkers for detection of esophageal cancer. PLoS ONE. 2013;8(4):e57502.

10. Mann $\mathrm{M}$, et al. The coming age of complete, accurate, and ubiquitous proteomes. Mol Cell. 2013;49(4):583-90.

11. Mallick P, Kuster B. Proteomics: a pragmatic perspective. Nat Biotechnol. 2010;28(7):695-709.

12. Liu F, et al. Quantitative proteomic analysis of gastric cancer tissue reveals novel proteins in platelet-derived growth factor b signaling pathway. Oncotarget. 2017;8(13):22059-75.

13. Maurya $P$, et al. Proteomic approaches for serum biomarker discovery in cancer. Anticancer Res. 2007;27(3A):1247-55.

14. Roessler M, et al. Identification of PSME3 as a novel serum tumor marker for colorectal cancer by combining two-dimensional polyacrylamide gel electrophoresis with a strictly mass spectrometry-based approach for data analysis. Mol Cell Proteomics. 2006;5(11):2092-101.

15. Chen JY, et al. Identification of PA28beta as a potential novel biomarker in human esophageal squamous cell carcinoma. Tumour Biol. 2017;39(10):1010428317719780.

16. Tian G, et al. Quantitative dot blot analysis (QDB), a versatile high throughput immunoblot method. Oncotarget. 2017;8(35):58553-62.

17. Njei B, McCarty TR, Birk JW. Trends in esophageal cancer survival in United States adults from 1973 to 2009: a SEER database analysis. J Gastroenterol Hepatol. 2016;31(6):1141-6.

18. Tan C, et al. Potential biomarkers for esophageal cancer. Springerplus. 2016;5:467.

19. Bird-Lieberman EL, et al. Population-based study reveals new riskstratification biomarker panel for Barrett's esophagus. Gastroenterolog. 2012:43(4):927-35e3

20. Wang $Q$, et al. Expression of epidermal growth factor receptor is an independent prognostic factor for esophageal squamous cell carcinoma. World J Surg Oncol. 2013;11:278.

21. Zhang J, et al. Potential diagnostic value of serum p53 antibody for detecting esophageal cancer: a meta-analysis. PLOS ONE. 2012:7(12):e52896.

22. Qi Y, et al. Comparative proteomic analysis of esophageal squamous cell carcinoma. Proteomics. 2005;5(11):2960-71. 
23. Xiong T, et al. An esophageal squamous cell carcinoma classification system that reveals potential targets for therapy. Oncotarget. 2017;8(30):49851-60.

24. Cheng $C$, et al. Whole-genome sequencing reveals diverse models of structural variations in esophageal squamous cell carcinoma. Am J Hum Genet. 2016;98(2):256-74.

25. Hou G, et al. Biomarker discovery and verification of esophageal squamous cell carcinoma using integration of SWATH/MRM. J Proteome Res. 2015;14(9):3793-803.

26. Samara P, et al. Prothymosin alpha: an alarmin and more. Curr Med Chem. 2017;24(17):1747-60.

27. Covelo G, et al. Prothymosin alpha interacts with free core histones in the nucleus of dividing cells. J Biochem. 2006;140(5):627-37.

28. Manrow RE, et al. Nuclear targeting of prothymosin alpha. J Biol Chem. 1991;266(6):3916-24.

29. Perez-Estevez A, et al. A 180-kDa protein kinase seems to be responsible for the phosphorylation of prothymosin alpha observed in proliferating cells. J Biol Chem. 1997;272(16):10506-13.

30. Barcia $M G$, et al. Prothymosin alpha is phosphorylated in proliferating stimulated cells. J Biol Chem. 1993;268(7):4704-8

31. Barbeito $P$, et al. Prothymosin alpha interacts with SET, ANP32A and ANP32B and other cytoplasmic and mitochondrial proteins in proliferating cells. Arch Biochem Biophys. 2017;635:74-86.

32. Karetsou Z, et al. Prothymosin alpha associates with the oncoprotein SET and is involved in chromatin decondensation. FEBS Lett. 2004;577(3):496-500.
33. Seo SB, et al. Regulation of histone acetylation and transcription by INHAT, a human cellular complex containing the set oncoprotein. Cell. 2001;104(1):119-30

34. Wang J, et al. PTMA, a new identified autoantigen for oral submucous fibrosis, regulates oral submucous fibroblast proliferation and extracellular matrix. Oncotarget. 2017:8(43):74806-19.

35. Moreira $\mathrm{D}$, et al. The influence of phosphorylation of prothymosin alpha on its nuclear import and antiapoptotic activity. Biochem Cell Biol. 2013;91(4):265-9.

36. Ha SY, et al. Expression of prothymosin alpha predicts early recurrence and poor prognosis of hepatocellular carcinoma. Hepatobiliary Pancreat Dis Int. 2015;14(2):171-7.

37. Zhang $M$, et al. Increased expression of prothymosin-alpha, independently or combined with TP53, correlates with poor prognosis in colorectal cancer. Int J Clin Exp Pathol. 2014;7(8):4867-76.

38. Tsai YS, et al. Aberrant prothymosin-alpha expression in human bladder cancer. Urology. 2009;73(1):188-92.

39. Tsai YS, et al. Loss of nuclear prothymosin-alpha expression is associated with disease progression in human superficial bladder cancer. Virchows Arch. 2014:464(6):717-24.

40. Chen $\mathrm{K}$, et al. Prothymosin-alpha and parathymosin expression predicts poor prognosis in squamous and adenosquamous carcinomas of the gallbladder. Oncol Lett. 2018;15(4):4485-94.
Ready to submit your research? Choose BMC and benefit from:

- fast, convenient online submission

- thorough peer review by experienced researchers in your field

- rapid publication on acceptance

- support for research data, including large and complex data types

- gold Open Access which fosters wider collaboration and increased citations

- maximum visibility for your research: over $100 \mathrm{M}$ website views per year

At BMC, research is always in progress.

Learn more biomedcentral.com/submissions 